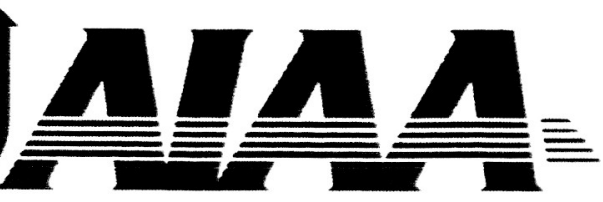

AIAA 2005-1059

Pressure-Sensitive Paint Investigation of Double-Delta Wing Vortex Flow Manipulation

Gary E. Erickson

NASA Langley Research Center

Hampton, Virginia

Hugo A. Gonzalez

Naval Air Systems Command

Patuxent River, Maryland

43 ${ }^{\text {rd }}$ AIAA Aerospace Sciences Meeting \& Exhibit 10-13 January 2005

Reno, Nevada

For permission to copy or republish, contact the American Institute of Aeronautics and Astronautics 1801 Alexander Bell Drive, Suite 500, Reston, VA 20191 


\title{
Pressure-Sensitive Paint Investigation of Double-Delta Wing Vortex Flow Manipulation
}

\author{
Gary E. Erickson * \\ NASA Langley Research Center \\ Hampton, Virginia \\ Hugo A. Gonzalez ${ }^{+}$ \\ Naval Air Systems Command \\ Patuxent River, Maryland
}

\begin{abstract}
A pressure-sensitive paint (PSP) technique was applied in a wind tunnel experiment in the NASA Langley Research Center 8-Foot Transonic Pressure Tunnel to quantify the effect of wing fillets on the global vortex-induced surface static pressure field about a sharp leading-edge $76^{\circ} / 40^{\circ}$ double delta wing, or strake-1ing, model at subsonic and transonic speeds. Global calibrations of the PSP were obtained at $M=0.50,0.70$, $0.85,0.95$, and 1.20, a Reynolds number per unit length of 2.0 million, and angles of attack from 10 degrees to 20 degrees using an in-situ method featuring the simultaneous acquisition of electronically-scanned pressures (ESP) at discrete locations on the model. The mean error in the PSP measurements relative to the ESP data was approximately 2 percent or less at $M=0.50$ to 0.85 but increased to several percent at $M=0.95$ and 1.20. The PSP pressure distributions and pseudo-colored planform view pressure maps clearly revealed the vortex-induced pressure signatures at all Mach numbers and angles of attack. Small fillets having a parabolic or diamond planform situated at the strake-wing intersection were designed to manipulate the vortical flows by; respectively, removing the leading-edge discontimuity or introducing additional discontimuities. The fillets caused global changes in the vortex-dominated surface pressure field that were effectively captured in the PSP measurements. The vortex surface pressure signatures were compared to available off-surface vortex cross-flow structures obtained using a laser vapor screen (LVS) flow visualization technique. The fillet effects on the PSP pressure distributions and the observed leading-edge vortex flow characteristics were consistent with the trends in the measured lift, drag, and pitching moment coefficients.
\end{abstract}

\footnotetext{
* Aerospace Technologist. Configuration Aerodynamics Branch

+ Aerospace Engineer. Air Vehicle Engineering

Department. Senior Member. AIAA

Copyright $C$ by the American Institute of Aeronautics and Astronautics. Inc. No copyright is asserted in the United States under Title 17. U.S. Code. The U.S Government has a royaltyfree license to exercise all rights under the copyright claimed herein for Government Purposes. All other rights are reserved by the copyright owner
}

\section{Introduction}

Pressure-sensitive paint is an optical-based technique that is frequently used for global surface static pressure measurements in wind tunnel testing of atmospheric flight and groundbased vehicle configurations. References 1 and 2 describe some of the early applications of PSP for field measurements in aerodynamic testing. A PSP system based on the work described in 
reference 2 was established in the NASA Langley Research Center (NASA LaRC) 8-Foot Transonic Pressure Tunnel (8-Foot TPT) in 1994. Reference 3 describes an application of the 8-Foot TPT PSP system in mid-1994 featuring a scientific-grade digital camera to measure the global surface static pressures on a slender, faceted missile model. The current report summarizes the results obtained in early 1994 using a developmental system with a conventional video camera in which the vortexinduced surface pressure field was imaged on a sharp leading-edge, $76^{\circ} / 40^{\circ}$ double delta wing model. The primary objectives of this experiment were two-fold: (1) to develop experience in the application of a global pressure measurement system in a transonic testing environment and (2) to manipulate the vortex flows about a generic double delta wing with small fillets located at the leading-edge sweep discontinuity. The latter objective is based on the belief that affecting the vortex shedding process at the wing planform juncture offers potential control of the vortex trajectories, mutual interactions, and breakdown characteristics. The topology of the vortexdominated flow field about the $76^{\circ} / 40^{\circ}$ double delta wing model is applicable to atmospheric flight vehicles that develop vortical flows in high-lift conditions during air combat maneuvers and take-off and landing. Reference 4 provides a review of some of the more recent fundamental studies of double-delta wing vortex flows, including experimental and computational studies of the current $76^{\circ} / 40^{\circ}$ double delta wing geometry with baseline, parabolic, and diamond planform fillets. The present investigation was part of a cooperative vortex flow research program initiated in the 1990's involving NASA Langley Research Center in Hampton, Virginia and the United States Naval Air Warfare Center in Warminster, Pennsylvania (now consolidated with the Naval Air Systems Command). PSP, ESP, six-component forces and moments, and LVS flow visualization results are summarized in reference 4 in which the $76^{\circ} / 40^{\circ}$ double delta wing model was tested with baseline, linear, parabolic, and diamond fillets at subsonic speeds in the NASA Langley Research Center 7- by 10Foot High Speed Tunnel. This cooperative investigation was extended to transonic speeds in two experiments performed in the 8-Foot TPT. The first experiment, designated Test 1052, featured the acquisition of ESP and sixcomponent force and moment measurements on the unpainted model with the full inventory of linear, parabolic, and diamond fillets. LVS flow visualization was also conducted on the model with baseline fillet at transonic Mach numbers. The second experiment, designated Test 1060 , focused on PSP applications to the baseline double delta wing model and a selected fillet from the parabolic and diamond families. The results from Test 1060 are the subject of the current paper, which focuses on the (1) global calibrations of the PSP using discrete measurements from an onboard ESP module; (2) comparison of the calibrated PSP distributions obtained on the baseline, parabolic, and diamond fillets; (3) comparison of the pressure distributions with available LVS images from Test 1052 and from reference 4; and (4) correlation of the PSP surface pressure measurements and LVS images with the trends in the model lift, drag, and pitching moment coefficients. It is noted that the PSP system used in the 8-Foot TPT was transferred to the NASA LaRC Unitary Plan Wind Tunnel (UPWT) upon the closure of the former facility in 1995. Consequently, the description of the PSP system presented herein provides relevant historical material on the upgraded system currently in use at UPWT. Details of the UPWT PSP system are provided in reference 5.

\section{Nomenclature}

$b \quad$ reference span, 16.326 inches

$c$ reference chord, 16.000 inches

$C_{A} \quad$ axial force coefficient, $\frac{\text { Axial Force }}{q_{x} S_{\text {ref }}}$

$C_{D} \quad$ drag coefficient, $\frac{\text { Drag Force }}{q_{x} S_{\text {ref }}}$

$C_{L} \quad$ lift coefficient, $\frac{\text { Lift Force }}{q_{\infty} S_{\text {ref }}}$ 
$C_{m}$ pitching moment coefficient.

$$
\frac{\text { Pitching Moment }}{q_{s} S_{r e f} c}
$$

$C_{V} \quad$ normal force coefficient.

$$
\frac{\text { Normal Force }}{q_{x} S_{r e f}}
$$

$C_{p} \quad$ upper surface static pressure coefficient. $\left(p-p_{x}\right) / q_{x}$

$C_{p, y} \quad$ vacuum pressure coefficient. $-2 / \gamma M^{2}$

$C_{p}^{*} \quad$ pressure coefficient corresponding to the local speed of sound.

$$
\frac{2}{\gamma M^{2}}\left\{\left[\frac{(\gamma-1) M^{2}+2}{\gamma+1}\right]^{35}-1\right\}
$$

$C_{p . P S P}$ PSP pressure coefficient

$\widehat{C}_{p, P S P}$ point estimate of the mean response at a specified PSP pixel location

ESP electronically-scanned pressure

$E S P_{i}$ pressure measurement at $i^{\text {th }}$ orifice, pounds per square inch (psi)

$I / I_{0}$ Intensity ratio at a given pixel location

LVS laser vapor screen

$M \quad$ free-stream Mach number

MRC moment reference center, M.S. 11.723

M.S. model station, inches

$N \quad$ number of ESP taps

$p \quad$ local static pressure, pounds per square foot (psf)

$p_{0} \quad$ stagnation pressure, $\mathrm{psf}$

$p_{,} \quad$ free-stream static pressure, psf

$P S P$ pressure-sensitive paint

$P S P_{i} \quad$ pressure measurement at PSP pixel location corresponding to $i^{\text {th }}$ ESP calibration orifice. psi

$q_{x} \quad$ free stream dynamic pressure, psf

Re Reynolds number per foot $s \quad$ local semispan measured from the wing centerline to the wing leading edge or wing tip. inches

$s\left(\hat{C}_{p, P S P}\right)$ Estimated standard deviation of the mean PSP pressure coefficient response $S_{\text {ref }} \quad$ reference area, 111.178 square inches

$t$ percentile from the Student $s \mathrm{t}$ distribution

$T_{0} \quad$ stagnation temperature. degrees

Fahrcnhcit

$x \quad$ local axial distance along the wing centerline chord measured from the wing apex, inches

$y \quad$ local semispan distance measured from the wing centerline, positive to the right. inches

$\alpha \quad$ angle of attack, degrees

$\alpha_{s} \quad$ level of statistical significance

$\varepsilon \quad$ mean relative error. percent

$\gamma \quad$ ratio of specific heats

\section{Model Description and Test Apparatus}

The model used in this test was a generic double delta wing configuration that was designed and fabricated for surface pressure and force and moment testing in subsonic and transonic wind tunnel facilities. The 0.375 -inchthick stainless steel wing featured a flat upper surface and sharp, beveled leading, side, and trailing edges. The leading-edge sweep angles of the highly-swept forward section, or strake, and the main wing panel were $76^{\circ}$ and $40^{\circ}$. respectively. A fiberglass housing was attached to the lower surface of the wing and served as a protective cover for the electronically-scanned pressure and six-component strain-gage balance instrumentation. Planview and sideview illustrations in figures 1 and 2 show the dimensional details of the model with the baseline fillet. The moment reference center (MRC) was located at M.S. 11.723 , or 73.27 percent of the wing centerline chord. The MRC location coincided with that used in references 6 
and 7 on a similar double delta wing planform. Three series of strake-wing intersection fillet shapes were fabricated to manipulate the double delta wing vortex flows and were categorized based on planform: linear, parabolic, and diamond. The linear and diamond fillets added additional leading-edge discontinuities, from which additional vortices were expected to originate, while the parabolic fillets removed the strake-wing junction discontinuity. Three fillet sizes based on the total fillet area (left and right fillets) expressed as a percentage of the model reference area were fabricated: $0.5 \%, 1 \%$, and $2.5 \%$ for linear and diamond, and $0.5 \%$, and $1 \%$ for parabolic. (A $2.5 \%$ parabolic fillet was prohibitively large.) The $1 \%$ parabolic and diamond fillets were selected for the PSP experiment, since previous experience (ref. 4) indicated that these fillet shapes, considered with the baseline configuration, would provide three distinctly-different flow fields and, therefore, serve as reasonable benchmarks to assess the PSP effectiveness. The sketches in figures 3 and 4 contain the geometry details of the $1 \%$ parabolic and diamond fillets. The $1 \%$ linear fillet, which was not used in the PSP testing, is illustrated in figure 5. The photographs in figure 6 show the model installed in the wind tunnel test section, and figure 7 is a close-up photograph of the model lower surface and the fiberglass instrumentation housing. A photograph of the model with PSP coating applied to the upper surface is presented in figure 8.

The model incorporated a total of 47 static pressure orifices having 0.012 -inch diameter distributed in three spanwise rows on the wing upper surface. The three rows were on the lefthand side of the wing at nondimensional axial locations, $x / c$, of $0.25,0.75$, and 0.90 , which correspond, respectively, to $25 \%, 75 \%$, and $90 \%$ of the distance, $x$, measured from the apex along the wing centerline chord, $c$. The orifice nondimensional semispan location, $y / s$, is expressed in terms of the semispan distance, $y$, measured from the wing centerline divided by the wing local semispan, $s$. Consequently, $y / s$ values of 0.0 and -1.0 correspond to the wing centerline and the left wing leading edge (or left wing tip), respectively.

The model surface pressures were measured using a single internally-mounted, 48-port ESP module. The shape of the lower surface instrumentation housing was dictated by the volumetric requirements of the ESP module and its electronics cable; the ESP calibration and reference lines; and the bundle of flexible tubing that jumpered the 47 stainless steel pressure lines from the model to the slant-line tubing on the ESP module head. The ESP module was a 10 pounds per square inch differential (psid) pressure transducer which was referenced to the tunnel plenum pressure. Full on-line calibrations of the ESP transducers were performed at each change in the free-stream Mach number. The manufacturer-specified uncertainty in the pressure measurement as a percent of full-scale was $+/-0.05$ percent for the 10 psid module. A table of the uncertainties in the ESP measurements expressed in terms of the surface static pressure coefficient for the range of test conditions is presented in the Wind Tunnel Facility and Test Conditions section. The mean error in the PSP pressure measurements relative to the ESP data, and PSP error bands corresponding to $95 \%$ confidence intervals, are presented in the Discussion of Results section.

Transition grit was not applied to the model, since the flow was assumed to separate at the sharp leading edges at all conditions of interest in the current experiment. In addition, a suitable gritting strategy based on the criteria in reference 8 to cause transition of the boundary layer associated with vortex-induced reattached flow on the wing upper surface has not been established. Reference 9 summarizes many of the challenges associated with transition grit applications for high-angle-of-attack wind tunnel and flight testing.

The model was instrumented with an internally-mounted, strain-gage balance designated $846 \mathrm{~B}$ to measure the six force and 
moment components. The uncertainties in the balance force and moment measurements as a percent of full-scale balance output based on a full calibration using the method described in reference 10 are listed in Table 1 . The uncertainty in the body-axis aerodynamic force and moment coefficients at the various test conditions are summarized in the Wind Tunnel Facility and Test Conditions section.

\begin{tabular}{|c|c|c|}
\hline Component & $\begin{array}{c}\text { Component } \\
\text { Limits }\end{array}$ & $\begin{array}{c}\text { Uncertainty } \\
\text { (\% Full } \\
\text { Scale) }\end{array}$ \\
\hline $\begin{array}{c}\text { Normal } \\
\text { Force }\end{array}$ & $\pm 700 \mathrm{lbs}$ & \pm 0.05 \\
\hline Axial Force & $85 \mathrm{lbs}$ & \pm 0.16 \\
\hline $\begin{array}{c}\text { Pitching } \\
\text { Moment }\end{array}$ & $\pm 1750 \mathrm{in}-\mathrm{lbs}$ & \pm 0.04 \\
\hline
\end{tabular}

Table 1. NASA LaRC $846 B$ strain gage balance measurement uncertainties.

An adapter block was mounted to the wing lower surface to allow the installation of the balance. The rearward extent of the instrumentation housing was based on a requirement to shield the entire length of the balance during wind-on conditions. Balance and ESP measurements were obtained simultaneously with the PSP image acquisition. Numerous check loads were applied at prescribed locations on the model using a handheld force gage or calibrated weights to verify that the ESP electronics cable and reference and calibration lines that spanned the balance were not affecting the balance output.

Balance chamber pressures were not recorded and, consequently, the axial force was not corrected to a condition of free-stream static pressure acting over the model chamber area. Corrections for test section flow angularity were not applied, since previous testing of models of comparable size in the 8-Foot TPT indicated these effects to be negligible. Blockage and wall interference corrections were not applied to the test data because of the relieving effect of the test section slots.

\section{Wind Tunnel Facility and Test Conditions}

The investigation was conducted in the NASA LaRC 8-Foot TPT. This wind tunnel facility was designed for operation as a continuous-flow, closed-return, variablepressure wind tunnel with control capability to independently vary Mach number, stagnation pressure, stagnation temperature, and humidity. The test section was square with corner fillets and a cross-sectional area approximately equivalent to that of an 8-foot-diameter circle. The top and bottom walls of the test section were axially slotted to permit a continuous variation of the test section Mach number from 0.2 to 1.2: the slot-width contour provided a gradient-free test section 50 inches long for Mach numbers equal to or greater than 1 , and 100 inches long for Mach numbers less than 1 . The stagnation pressure could be varied from 0.25 to 2 atmospheres. Reference 11 provides a detailed description of the 8-Foot TPT. Note that this facility was permanently closed in 1995.

The PSP testing was performed at freestream Mach numbers of $0.50 .0 .70,0.85,0.95$. and 1.20 at a Reynolds number of 2.0 million per foot and a stagnation temperature of 80 degrees Fahrenheit. The ESP measurements and the processed PSP images that are presented in this report were acquired at angles of attack from 10 degrees to 20 degrees in 2-degree increments at all Mach numbers. The test conditions are summarized in Table II. Table III shows the estimated uncertainties in the surface static pressure coefficient and the normal force, axial force, and pitching moment coefficients for the test conditions listed in Table II. The model angle of attack and angle of sideslip were determined via appropriate Euler angle transformations using the output from an accelerometer mounted in the base of the main sting support. output from a potentiometer installed in a yaw coupler mechanism, and angular deflection of the model, balance, and sting support system determined from pre-test calibrations. 


\begin{tabular}{|c|c|c|c|c|c|}
\hline$M$ & $\begin{array}{c}q_{x} \\
(\mathrm{psf})\end{array}$ & $\begin{array}{c}p_{x} \\
(\mathrm{psf})\end{array}$ & $\begin{array}{c}p_{0} \\
(\mathrm{psf})\end{array}$ & $\begin{array}{c}R e \\
\left(10^{-6}\right)\end{array}$ & $\begin{array}{c}T_{0} \\
\left({ }^{0} F\right)\end{array}$ \\
\hline 0.50 & 206 & 1175 & 1398 & 2.0 & 80 \\
\hline 0.70 & 273 & 793 & 1102 & 2.0 & 80 \\
\hline 0.85 & 314 & 619 & 995 & 2.0 & 80 \\
\hline 0.95 & 337 & 532 & 953 & 2.0 & 80 \\
\hline 1.20 & 379 & 375 & 913 & 2.0 & 80 \\
\hline
\end{tabular}

Table II. Test conditions for the double delta wing model experiment in the NASA LaRC 8-Foot TPT.

\begin{tabular}{|c|c|c|c|c|}
\hline$M$ & $C_{p}$ & $C_{N}$ & $C_{A}$ & $C_{m}$ \\
\hline 0.50 & \pm .0035 & \pm .0022 & \pm .00086 & \pm .00028 \\
\hline 0.70 & \pm .0026 & \pm .0017 & \pm .00065 & \pm .00021 \\
\hline 0.85 & \pm .0023 & \pm .0014 & \pm .00056 & \pm .00018 \\
\hline 0.95 & \pm .0021 & \pm .0013 & \pm .00052 & \pm .00017 \\
\hline 1.20 & \pm .0019 & \pm .0012 & \pm .00046 & \pm .00015 \\
\hline
\end{tabular}

Table III. Estimated uncertainties in the surface static pressure coefficient and the normal force, axial force, and pitching moment coefficients.

The majority of the LVS flow visualization images that are presented in this report were obtained in 8-Foot TPT Test 1052. Flow visualization was performed only on the unpainted double delta wing model with baseline fillet at $M=0.85,0.95$, and 1.20 . LVS flow visualization was not conducted at $M=0.50$ and 0.70 , since the estimated amount of water injection to promote local condensation of water vapor in the 8-Foot TPT test section was prohibitive. LVS flow visualization results obtained on the model with baseline, $1 \%$ parabolic, and $1 \%$ diamond fillets in reference 4 in the NASA LaRC 7- by 10-Foot High Speed Tunnel at $M=0.50$ and 0.70 are also presented. The tunnel stagnation pressure was set by atmospheric conditions in this facility. The corresponding Reynolds numbers at $M=0.50$ and 0.70 were approximately 3.0 million per foot and 3.6 million per foot, respectively. A detailed description of the 7 - by 10 -Foot High Speed Tunnel is provided in reference 12 .

\section{Experimental Techniques}

\section{Pressure-Sensitive Paint Technique}

The PSP method is based on the oxygenquenching characteristics of certain luminescent materials. The emitted light intensity varies inversely with the local oxygen partial pressure and, therefore, the air pressure, since oxygen is a fixed mole fraction of air. A PSP formulation typically consists of three components. The luminescent material (luminophore) is the sensor component. For oxygen quenching to occur, the luminophore must be soluble in a suitable binder material. Finally, a compatible solvent is used for the application of the paint, via a spray gun, to the test article. Prior to the paint application, the model surface is primed with white paint. The white undercoat to the PSP coating serves a critical function in that it amplifies the PSP emission signal (reference 2). Certain characteristics of PSP coatings induce measurement error: photodegradation and temperature sensitivity. Specifically, the emission response of the PSP decreases with time of exposure to the excitation radiation, and the luminescence intensity is sensitive to changes in the temperature. A formulation that was successfully applied at the 8-Foot TPT was designated IEMA/PtT(PFP)P, which used a proprietary University of Washington copolymer (IEMA). Laboratory calibrations at LaRC indicated that the Stern-Volmer characteristics (reference 2) were very linear, and photodegradation was reduced compared to prior-generation paints. This formulation was not the most advanced in use by other facilities at that time; however, it proved a robust and responsive formulation for use at the low static pressures typical of the transonic testing at the 8Foot TPT.

The intensity of the light emitted by the PSP is proportional to the excitation light that is absorbed. A stable illumination source must be used that is tailored to the absorption wavelength band of the PSP coating. Ultraviolet long wave (365 nm), 250-watt lamps connected to a regulated power supply were used in continuous 
mode to provide the illumination source in the 8-Foot TPT system. The optical filters attached to these lamps allowed passage of light at the absorption wavelength of the coating but prevented transmission of light at the luminescence wavelengths that could compromise the images acquired by the PSP camera. Figure 9 presents a simplified sketch of the main components of the 8-Foot TPT PSP system.

Electronic CCD imaging devices of two types were used in Test 1060: conventional video and scientific grade digital cameras. The PSP system in use at 8-Foot TPT at the time of this test featured an 8-bit-resolution image acquisition and processing system using a standard NTSC format video camera. The PSP pressure distributions that are presented in this paper were obtained using this camera. A second system featuring a thermoelectrically-cooled CCD digital camera of 14-bit resolution and $1024 \times 1024$ pixel array was installed in parallel with the 8-Foot TPT hardware. This system was independently operated by personnel from an instrumentation research organization at NASA LaRC and provided an initial evaluation of a superior camera having low noise, excellent linear response, and good signal-to-noise ratio. The conventional video cameras continued to be used as monitoring devices in later tests with an 8-Foot TPT PSP system that was upgraded with a scientific-grade digital camera. In this capacity, the standard video cameras had the advantage of providing real-time viewing of the PSP response to aerodynamic flow changes induced, for example, by vortices and shock waves.

A dark-level correction was applied to all wind-off and wind-on images to subtract out the CCD dark current and "noise" of the overall imaging system. Optical filters centered about $650 \mathrm{~nm}$ were installed on the conventional video and scientific-grade digital cameras to permit the passage of the luminescence emission wavelengths, while preventing the transmission of the excitation light source wavelengths to the acquisition cameras. The incursion of extraneous sources of light from the plenum area into the test section was prevented by turning off all light sources within the plenum and sealing all optical view ports into the plenum with "light-tight" coverings.

Acquisition of the PSP images using the conventional video system was controlled by a computer workstation in the 8-Foot TPT control room. A personal computer (PC) with a proprietary interface was used to control the scientific-grade digital camera system. The cable run length between the host computers and the cameras installed above the test section was approximately 100 feet. The power supply for the conventional video and the electronic control and liquid cooling units for the digital camera were positioned in proximity to the cameras. Consequently, the primary imaging system components were exposed to the low-pressure environment in the plenum chamber surrounding the test section. PSP images were stored on the workstation hard disk and on a high-capacity optical disk on the PC for off-line processing and archiving. Image processing and paint calibrations were performed primarily on the workstation using the software package described in reference 13 and referred to as PAINTCP. The images that were obtained with the digital camera were in a proprietary format that was incompatible with PAINTCP. Consequently, a developmental version of a PCbased PSP image processing application described in reference 14 was used to provide higher-quality pseudo-colored ratioed images. These qualitative results from the digital camera supplement the calibrated PSP pressure distributions derived from the conventional video that are presented in this report.

Optical access to the 8-Foot TPT test section was provided by several schlieren windows on both sidewalls and three identical 4-inch wide by 16-inch long optical-quality windows positioned along the centerline of the test section ceiling. The imaging cameras and ultraviolet light sources were installed in the test section ceiling 
in order to image the upper surface of the double delta wing model at high angles of attack. Thermally-controlled enclosures were used to safeguard the imaging cameras. Temperature control within the enclosures was achieved by vortex-tube coolers attached to each unit. Coolers were also installed to the four UV lamp heads to avoid temperature-induced damage to the electronic circuitry that might occur in the low-pressure environment within the plenum region. In addition, vortex coolers were used to provide cooling air along the optical windows to avoid thermal stresses induced by the UV lamps, which were in proximity to the window surface. A total of four 250-watt UV lamps were installed along the ceiling centerline, two in front of and two behind the imaging cameras. Metal shields were placed between the cameras and lamps to prevent electromagnetic interference that could damage the camera's sensitive electronic components. This situation might arise as the result of power cycling of the UV lamps while the cameras were operational. Previous testing experience at the 8-Foot TPT indicated the vibration level within the ceiling region was sufficiently low so that preventative measures for safe operation of the digital camera were unnecessary. The imaging and illumination devices were attached to regulated power sources, which could be independently controlled (on/off) from the wind tunnel control room. A partial view of the complex hardware installation on top of the wind tunnel test section is revealed in the photograph in figure 10 . The host computer system used to control the conventional video camera is shown in figure 11 .

The paint application and curing process required one working shift to complete. This operation required a skilled painter equipped with protective gear, including full face mask and a continuous air supply. The double delta wing model was instrumented with discrete surface static pressure orifices plumbed to an internal, 10 psid ESP module. A module with purge air capability was not available at the time of this experiment. Consequently, the pressure rows were masked off with 0.10 -inch wide tape during the painting process. Approximately 4 hours were required for the curing of the base coat, and a comparable period of time was allotted after the PSP coating was applied. The PSP image registration process required that reference marks, or control points, be placed on the model. The locations of these registration marks were defined by placing on the fullycured PSP coating a transfer sheet containing a 1:1 scale drawing of the double delta wing with pre-punched holes. After the hole centers were marked, the template was removed and black dots were drawn on the model using a plastic circle template and marker pen. Latex gloves were worn during this process to avoid contamination of the PSP coating.

Wind-off images were acquired at several angles of attack with the test section pumped down to a low pressure of approximately 300 psf. This condition was more representative of the static pressure levels that existed on the painted model during wind-on runs, and it provided an opportunity to define a suitable integration time for the PC-based digital camera system.

Wind-on data acquisition consisted of the discrete pressures measured from the ESP taps and the PSP images at the desired angles of attack. Full on-line calibrations of the ESP modules were performed at each change in the Mach number, since the acquisition of highquality ESP data was essential to the in-situ PSP calibrations performed during the off-line image processing. The PSP illumination sources could not be shielded during the transitional phases of tunnel operation such as Mach number and angle of attack changes and ESP calibrations. Consequently, run times were kept to a minimum in order to limit the overall exposure time of the PSP coating. PSP image acquisition was performed independently of the data acquisition performed by the wind tunnel host computer. The test conditions, ESP data, and other parameters were obtained off-line for use in input files required by the PSP image 
processing software. A repeat set of wind-off images and dark images was acquired after the wind-on runs. Comparisons of the initial and final wind-off pixel intensities at the same camera integration times provided an indication of the level of photodegradation that had occurred.

The image processing method featured the subtraction of the dark image from the wind-off and wind-on images, identification of wind-off and wind-on control points, image registration. image ratioing, resection transform, and global calibration of the paint. Registration, or spatial alignment, of the two model images was performed to correct for nonalignment caused by model motion. A second-order biquadratic transform was used to align the wind-on image with the wind-off image. This process depended on finding the respective control points, or registration marks, which were used to determine the transform coefficients. The windoff and wind-on intensity field images were ratioed, and the intensity field of the resultant image was proportional to pressure (SternVolmer relation): A resection transform based on photogrammetry techniques was performed next, which related each point in the final intensity ratio image plane to a corresponding point on the model surface. The effectiveness of this transform depended on an accurate determination of the spatial locations of the model registration marks. The image mapping performed in this experiment was exclusively a 2-D plane view representation of the double delta wing model. Quantification of the pressure field in the final intensity ratio image required a calibration of the paint to determine the StemVolmer sensitivity coefficients. An "in situ" calibration method was applied, where the paint intensity was calibrated from the pressure tap data at spatially corresponding locations. The in-situ calibration process was iterative, since the first pass through the calibration rarely provided a completely satisfactory global match between the ESP and PSP pressure data. Because of the masking approach that was used during the paint process, the paint could not be calibrated at the exact locations of the pressure orifices. This required that the PSP image pixel locations used for calibration be offset from the orifices. In some instances, apparent nonuniformity of the paint thickness near the masking lines required additional offsets during the calibration procedure.

\section{Laser Vapor Screen Technique}

The vapor screen method of flow visualization has been used in wind tunnel testing for several decades to visualize vortices, vortex sheets, lines of flow separation and reattachment. and shock waves at subsonic, transonic, and supersonic speeds. Water is injected in sufficient quantity into the tunnel circuit, typically downstream of the supersonic nozzle or the diffuser section. to cause condensation of water vapor in the test section. At supersonic speeds, the temperature drop from the expansion in the supersonic nozzle causes the water vapor to condense into a fine fog. A laser is often used to produce an intense sheet of light that is projected into the test section in a plane perpendicular to the longitudinal axis of the tunnel or to the body axis of the model. The distribution of condensed water vapor and, consequently, the amount of scattered light within the plane of the light sheet is affected by the flow disturbances created by the model. This phenomenon permits the observation and documentation of vortex cross sections, for example, at high angles of attack. Condensation first appears in the free stream at supersonic speeds, so the vortical flows appear as dark regions in the absence of scattered light surrounded by a light background. At subsonic and transonic speeds, condensed water vapor generally first appears near the central region of the vortices, so the vortex cross sections appear as light regions within a darker background. A combination of the two light-scattering patterns often occurs at transonic speeds.

A fiber-optic-based laser vapor screen (LVS) system was established in the 8-Foot TPT in 1990 (reference 15) to visualize the vortexdominated flow fields about small-scale models of fighter aircraft, commercial transport 
airplanes, and missiles at subsonic and transonic speeds. A simplified sketch of the 8-Foot TPT system is shown in figure 12, and a detailed description of this system is provided in reference 15. A fiber optic cable delivered a beam from an argon laser located outside the tunnel plenum to a light sheet optics package located in the ceiling of the test section. The optics package occupied the same region required by the PSP hardware, so the setup of the two techniques was mutually exclusive in this facility. Consequently, application of the two techniques was performed in separate phases of the experiment. The fiber-optic-based beam delivery system contained five principal components: laser-to-fiber coupler, armored fiber optic cable, remote light sheet generator, rotating mirror, and optics motor controller. The system was designed to be used with virtually any argon-ion laser system operating in either continuous wave $(\mathrm{CW})$ or multimode with beam diameters from approximately 0.0315 inches to 0.0709 inches. The light sheet optics package allowed variation of the sheet thickness, divergence or spread of the light sheet, and sheet rotation relative to the model. A 3- by 3-inch mirror mounted onto a rotational stage with 360 degrees of continuous rotation directed the light sheet through the optical window and to the desired station on the model. The light sheet was aligned to be perpendicular to the model surface at approximately mid chord and an angle of attack of 16 degrees. Because the light sheet swept in an arc along the model, it was nonorthogonal with respect to the model surface at all other conditions.

Water was injected into the tunnel circuit from a 150-gallon tank of deionized water located in a room on top of the plenum shell to an array of six atomizer nozzles installed in the ceiling region of the diffuser section. The amount of water that was injected into the tunnel was remotely regulated from the wind tunnel control room via a solenoid switch and a onehorsepower pump positioned on the discharge side of the water tank.
Documentation of the LVS images was obtained using a miniature video camera with 360 television lines of horizontal resolution and a fixed focal length lens contained in a cylindrical housing mounted onto the model sting support system. This camera provided a perspective aft of the model which looked upstream along the model centerline. The video image perspective remained constant throughout the pitch angle range because there was no relative motion between the camera and the model. The video image perspective did vary, however, if the model yaw angle was changed. Selected portions of the videotape recording were digitized and converted to AVI format using a video frame grabber installed in a personal computer. The frame grabber software allowed the precise capture and enhancement of the individual LVS frames that appear in this paper.

\section{Discussion of Results}

\section{PSP Benefits and Accuracy}

The PSP pressure measurement technique allowed for a more detailed view of the vortexinduced pressure field on the double delta wing model upper surface compared to the three rows of discrete ESP taps. An advantage of the PSP technique is that every pixel in the painted portion of the image is effectively a pressure tap, so the pressure distributions can be resolved to much greater detail in all applicable regions of the model.

Tables IV, V, and VI show the percent error and intervals corresponding to $+/-$ two sample standard deviations for the PSP pressure measurements relative to the ESP tap data for the baseline, parabolic, and diamond fillets, respectively. The selected test conditions were $M=0.50,0.70,0.85,0.95$, and 1.20 and $\alpha=20$ degrees. Listed in each table are the Mach number, the number of ESP taps used to calibrate the PSP, the range of pressure spanned by the ESP taps, the mean relative error in PSP measurement, and an interval corresponding to 
two sample standard deviations for the PSP measurements relative to the ESP data.

The mean relative error is calculated using the following equation from reference 16 :

$$
\varepsilon=\frac{\sum_{i=1}^{N}\left(100 \times \frac{\left|E S P_{i}-P S P_{i}\right|}{E S P_{i}}\right)}{N}
$$

where $\mathrm{ESP}_{\mathrm{i}}$ is the pressure value in psi at the $i^{\text {th }}$ pressure tap, PSP $_{i}$ is the the pressure value in psi using the PSP technique corresponding to $\mathrm{ESP}_{\mathrm{i}}, \mathrm{N}$ is the number of ESP taps used, and $\varepsilon$ is the mean relative error in pressure measurement using the PSP technique.

\begin{tabular}{|c|c|c|c|c|}
\hline$M$ & $N$ & $\begin{array}{c}\text { Range of } \\
\text { ESP } \\
\text { pressures } \\
\text { (psi) }\end{array}$ & $\varepsilon(\%)$ & $\begin{array}{c}2 \text { std. dev. } \\
\text { interval } \\
E S P_{i}-P S P_{i} \\
\text { (psi) }\end{array}$ \\
\hline 0.50 & 47 & $5.9-8.3$ & 0.5 & $+/-0.10$ \\
\hline 0.70 & 47 & $2.5-5.7$ & 1.0 & $+/-0.10$ \\
\hline 0.85 & 47 & $1.3-4.0$ & 1.7 & $+/-0.11$ \\
\hline 0.95 & 47 & $0.9-3.3$ & 3.5 & $+/-0.12$ \\
\hline 1.20 & 47 & $0.3-2.1$ & 11.1 & $+/-0.21$ \\
\hline
\end{tabular}

Table IV. Summary of PSP analysis results for five wind tunnel conditions: baseline fillet.

\begin{tabular}{|c|c|c|c|c|}
\hline$M$ & $N$ & $\begin{array}{c}\text { Range of } \\
\text { ESP } \\
\text { pressures } \\
\text { (psi) }\end{array}$ & $\varepsilon(\%)$ & $\begin{array}{c}2 \text { std. dev. } \\
\text { interval } \\
E S P_{i}-P S P_{i} \\
\text { (psi) }\end{array}$ \\
\hline 0.50 & 47 & $4.1-8.4$ & 1.5 & $+/-0.25$ \\
\hline 0.70 & 47 & $2.6-5.5$ & 2.1 & $+/-0.23$ \\
\hline 0.85 & 47 & $1.9-3.9$ & 2.0 & $+/-0.15$ \\
\hline 0.95 & 47 & $1.0-3.4$ & 2.8 & $+/-0.13$ \\
\hline 1.20 & 47 & $0.4-2.2$ & 8.6 & $+/-0.15$ \\
\hline
\end{tabular}

Table $V$. Summary of PSP analysis results for five wind tunnel conditions; parabolic fillet.

\begin{tabular}{|c|c|c|c|c|}
\hline$M$ & $N$ & $\begin{array}{c}\text { Range of } \\
\text { ESP } \\
\text { pressures } \\
\text { (psi) }\end{array}$ & $\varepsilon(\%)$ & $\begin{array}{c}2 \text { std. dev. } \\
\text { interval } \\
E S P_{r}-P S P_{i} \\
\text { (psi) }\end{array}$ \\
\hline 0.50 & 47 & $5.1-8.2$ & 0.5 & $+/-0.09$ \\
\hline 0.70 & 47 & $2.1-5.4$ & 1.4 & $+/-0.13$ \\
\hline 0.85 & 47 & $1.0-4.2$ & 2.0 & $+/-0.13$ \\
\hline 0.95 & 47 & $0.6-3.2$ & 3.8 & $+/-0.13$ \\
\hline 1.20 & 47 & $0.4-2.4$ & 5.1 & $+/-0.11$ \\
\hline
\end{tabular}

Table VI. Summany of PSP analysis results for five wind tunnel conditions; diamond fillet.

Tables IV, V, and VI indicate that the mean relative error in pressure measurement is approximately 2 percent or less at $M=0.50$, 0.70 , and 0.85 but increases to approximately 3 percent or higher at $M=0.95$. and 1.20. This trend is apparent for all three fillet configurations, which correspond to three independent applications of the PSP coating. Possible contributing factors are (1) error in the intensity measurement, which results in a larger relative error in the measurement of the lower pressures at the transonic speeds compared to the higher pressures at the subsonic speeds (reference 17 ); (2) increased model vibration at the transonic speeds; (3) more pronounced surface temperature variations at the transonic speeds (surface temperature measurements were not made during this experiment); (4) photodegradation effects; and (5) the presence of local condensation (humidity control was used in the 8-Foot TPT but instrumentation to measure humidity was not available). It is noted, however, that the magnitudes of the relative error and the two-standard-deviation intervals were encouraging, given the developmental status of the 8-Foot TPT PSP system and the conventional video imaging camera in use at the time of this experiment. 


\section{Comparison of ESP Pressure \\ Distributions for the Unpainted and \\ Painted Models}

The unpainted model was tested at the outset of Test 1060 in order to obtain pressure distributions for comparison to the painted model. Previous PSP testing on the double delta wing model in the NASA LaRC 7 - by 10 -Foot High Speed Tunnel (ref. 4) indicated that the paint coating could affect the vortex symmetry and breakdown characteristics at subsonic, high angle-ofattack conditions. This obtrusive effect could be quite pronounced if the paint coating was allowed to wrap around the sharp leading edges during the application process. Particular care was taken during the PSP application in the 8-Foot TPT experiment to avoid this situation. It was not known prior to Test 1060 , however, if the paint thickness (approximately $0.001 \mathrm{in}$. to 0.002 in.) and surface roughness compared to the unpainted model could also affect the vortex behavior at transonic speeds.

Figure 13 presents selected ESP distributions of the upper surface static pressure coefficient that were obtained on the unpainted model and painted model with baseline fillet at $\alpha=20$ degrees and $M=0.50,0.70,0.85,0.95$, and 1.20 . The results in figure 13 show reasonable quantitative agreement. Some differences are noted at the higher Mach numbers. However, the increased scatter may reflect the difficulty in repeating surface pressure measurements in conditions where separated flow and shock waves coexist, rather than an obtrusive effect of the PSP coating. In general, the unpainted and painted model comparisons provided assurance that the PSP coating was not causing a significant effect on the flow topology of interest in the current experiment.

\section{Comparison of PSP and ESP Pressure Measurements, Ratioed PSP Images, and LVS Flow Visualization}

Composite plots are presented for the baseline, parabolic, and diamond fillets in figures 14 through 64 showing the distributions of the calibrated PSP upper surface static pressure coefficient corresponding to the locations of the discrete ESP pressure orifices at the three axial measurement stations $x / c=0.25,0.75$, and 0.90 . The surface pressures are plotted against the local distance $y$ measured from the wing centerline, normalized by the local semispan, $s$. For example, values of the nondimensional semispan location $y / s=0.0$ and $\mathrm{y} / \mathrm{s}=-1.0$ respond to the wing centerline and the left wing leading edge, respectively. There were 9 discrete pressure orifices at $x / c=0.25$ and 19 orifices in each of the two stations at $x / c=0.75$ and 0.90 . The composite plots also include the corresponding ESP pressure measurements, false-colored PSP global pressure field response and, when available, LVS flow visualization images. All results were obtained at a sideslip angle of 0 degrees.

A global calibration of the PSP was obtained by selecting pixel locations in the processed PSP image that were as close as possible to the ESP pressure orifices but in a region where the paint thickness was considered uniform. There was an unpainted region about 0.10 inches wide centered about the pressure orifices. In addition, there was a transition region where the PSP was feathered into the unpainted area. A typical pixel location for calibration purposes was approximately 0.06 inches upstream or downstream of the orifice. PAINTCP performs a simple linear regression to compute the intercept and slope of the global calibration for each PSP image. The values of the intensity ratios and ESP pressure coefficients were also exported to a statistical software application (ref. 18) to conduct an independent linear regression and analysis of residuals. 
Specifically, the residuals for all of the estimated regression functions in this experiment were plotted and analyzed to confirm that the assumptions of normallydistributed errors and constancy of error variance were satisfied. In addition, checks were performed for the presence of outlying or influential observations. An assessment of the independence of error terms could not be made since the data in a given PSP image were not acquired in any time order.

The false-colored PSP pressure maps were created from the scientific-grade digital camera images using the PSP application software in ref. 14 . These images have undergone registration, ratioing. and resection transform. Color bars are not included, since each image was tailored to a specific combination of the angle of attack and Mach number to highlight the prominent features of the surface pressure response. In general, green, blue, and purple colors correspond to regions of low pressure (that is, higher suction pressures), with purple representing the highest suction pressure levels. Regions of higher surface pressures (lower suction pressures or slightly positive pressures) are represented by yellow and red colors.

The available LVS images are positioned above the appropriate pressure measurement stations. The LVS images are scaled relative to each other to reflect the growth of the vortices from the forward to aft portions of the wing. However, they are not scaled according to the pressure distribution plots. For example, the approximate location of the vortex center in the LVS image, if visible, cannot be transferred directly to the location of the vortex-induced suction pressure peak in the PSP and ESP distributions. The main purpose of these composite plots is to show the level of agreement between the two pressure measurement techniques and to provide pertinent information on the topology of the vortex flows that induce these pressure distributions.
The series of composite plots at each angle of attack corresponding to a specific fillet shape and Mach number combination are supplemented by a single plot showing the effect of the angle of attack on the calibrated PSP pressure distributions. These distributions are superimposed on an isometric view of the left side of the double delta wing model. The effect of angle of attack on the false-colored PSP images is also illustrated in an accompanying composite figure. Summary figures showing the effect of the Mach number on the false-colored PSP images at selected angles of attack are presented at the end of each section corresponding to a particular fillet geometry.

Inferences are made regarding regions of locally supersonic flow based on a comparison of the experimental pressure coefficients to the critical value at a given Mach number. The level of peak suction pressure coefficient relative to the vacuum pressure coefficient will also be inferred. Table VII shows the corresponding vacuum pressure and critical pressure coefficients for the Mach numbers considered in this experiment.

\begin{tabular}{|c|c|c|}
\hline$M$ & $C_{p . v}$ & $C_{p}^{*}$ \\
\hline 0.50 & -5.714 & -2.133 \\
\hline 0.70 & -2.915 & -0.779 \\
\hline 0.85 & -1.977 & -0.302 \\
\hline 0.95 & -1.583 & -0.088 \\
\hline 1.20 & -0.992 & N/A \\
\hline
\end{tabular}

Table VII. Vacuum and critical pressure coefficients.

\section{Baseline Fillet, $M=0.50$}

Comparisons of the distributions of the PSP and ESP upper surface static pressure coefficient at $M=0.50$ and $\alpha=16$ and 20 degrees are shown in figures 14(a) and 14(b), respectively. The pressure distributions are plotted on a common scale to facilitate comparisons of the vortex pressure signatures at the three measurement stations. The false-colored, ratioed PSP 
images provide a qualitative map of the surface pressure field response at each angle of attack, where regions of higher suction pressures (more negative pressure coefficients) are denoted by green, blue, and purple colors. Regions of lower suction pressures (less negative pressure coefficient) or small positive pressures are represented primarily by yellow and red colors. The intensity ratio scales and corresponding color coding were tailored to each angle of attack in order to extract important features of the pressure field response. Specification of a common intensity ratio scale for all angles of attack would have resulted in relatively large, uninterpretable white or black (saturated) regions in certain images. In general, the pressure signatures, or footprints, of the leading-edge vortices are revealed by narrow bands of green, blue, and/or purple colors that are bounded by regions of yellow and red colors. An abrupt change in color from green/blue/purple to yellow/red and an expansion of the vortex footprint are interpreted as the signature of a normal shock wave above the wing or the onset of vortex breakdown.

The PSP and ESP pressure distributions are in reasonable agreement at each angle of attack (figs. 14(a) and 14(b)). Both pressure measurement techniques reveal a region of higher suction pressures induced by the strake vortex at $x / c=0.25$. This region is coded green or blue in the ratioed PSP images. At $\alpha=16$ degrees (fig. 14(a)), the LVS images at $x / c=0.25$ reveal the strake vortex as a small circular region of local condensation. The PSP and ESP measurements show distinct suction pressure peaks induced by the strake and wing vortices at $x / c=0.75$ and $\alpha=16$ degrees (fig. 14(a)). The suction peak situated closer to the wing leading edge at $x / c=0.75$ and approximately $y / s=-0.65$ is induced by the wing vortex, whereas the strake vortex surface pressure footprint is located farther inboard at about $y / s=-0.40$. The wing vortex induces a higher suction pressure compared to the strake vortex at $\alpha=16$ degrees and $x / c=0.75$. The PSP image in fig. 14(a) shows corresponding purple color coding (or black coding, which indicates saturation for the selected intensity ratio scale) associated with the wing vortex compared to the light blue color assigned to the strake vortex. A large region of primarily yellow and red colors is typically observed between the strake vortices. This is a region of increased pressure associated with the vortex-induced reattached flow on the wing upper surface. Interestingly, the strake vortex flow is the most visible in the LVS images in fig. 14(a). This effect may be caused by more accumulation of water vapor condensate within the strake vortex, which has a comparatively greater leading-edge run length along which vorticity sheds and feeds into the strake vortical flow. The emergence of the strake vortex as a dominant feature in the double delta wing flow field is apparent in the pressure distributions and PSP and LVS images at both angles of attack. The character of the pressure distribution at $\alpha=16$ degrees and $x / c=0.75$ evolves from a distinct dualvortex pressure signature to a nearly single vortex footprint at $x / c=0.90$ (fig. 14(a)). At $\alpha=20$ degrees (fig. 14(b)), a single vortex pressure signature is apparent at all measurement stations. This trend reflects a direct interaction between the strake and wing vortices. The wing vortex is drawn inboard and upward from the wing surface as a result of this interaction, and its direct effect on the wing surface pressure field is eventually masked. There is evidence that the interacting wing and strake vortex system bursts over the aft portion of the wing at $\alpha=20$ degrees (fig. 14(b)). This phenomenon is manifested as a broadening of the pressure distribution and an overall reduction in the suction pressure level at $x / c=0.90$ in fig. $14(b)$, a pressure rise coded by yellow and red colors in the PSP image, and a diffusion of the LVS condensation pattern.

The effect of the angle of attack on the calibrated PSP pressure distributions at $x / c=$ 
0.25 .0 .75 , and 0.90 is shown in the isometric plot in figure 15. A consistent increase in the strake vortex-induced suction peak occurs at $x / c=0.25$ for the range of angle of attack from 10 to 20 degrees. At $x / c=0.75$. the wing vortex suction peak increases up to $\alpha=14$ degrees. This trend is followed by a decline and inboard movement of the wing vortex pressure signature at higher angles of attack. At $\alpha=$ 20 degrees, the wing vortex footprint in completely obscured as a result of its interaction with the strake vortex. The trend is similar, but occurs at lower angles of attack, at $x / c=0.90$. and the influence of vortex bursting is apparent in the pressure distribution at $\alpha=20$ degrees. The PSP pressure coefficients indicate that the flow on the double delta wing surface is subsonic. since they are all less than the critical pressure coefficient of -2.133 at this Mach number.

The distinct strake and wing vortex pressure signatures at $\alpha=10$ to 14 degrees. the mutual interaction of the two vortices and the emerging dominance of the strake vortex at higher angles of attack, and the onset of vortex breakdown at $\alpha \cong 20$ degrees can be inferred from the composite PSP ratioed images in figure 16.

\section{Baseline Fillet, $M=0.70$}

Comparisons of the distributions of the PSP and ESP upper surface static pressure coefficient at $M=0.70$ and $\alpha=16$ and 20 degrees are shown in figs. 17(a) and 17(b), respectively. Good agreement exists between the PSP pressure distributions and the ESP measurements used for the in-situ calibration at $x / c=0.25,0.75$, and 0.90 and both angles of attack. The interaction between the strake and wing vortices is less pronounced compared to $M=0.50$. For example, the wing vortex maintains a distinct pressure signature at $x / c=0.75$ up to the highest angle of attack of 20 degrees. Direct vortex interaction does occur at $x / c=$ 0.90 based on the transition from a twin- peak distribution to a single-peak pressure signature. Onset of vortex breakdown over the wing is more subtle as well. since the pressure distribution at $x / c=0.90$ remains peaked up to $\alpha=20$ degrees and a marked decline in the suction pressure level is not evident. A pressure rise in a region near the wing tip is suggested by the yellow and red color coding in the PSP image at this angle of attack, which may be the precursor to fully-established vortex breakdown upstream of the trailing edge. LVS images were not obtained at angles of attack greater than 16 degrees in the testing in ref. 4 because of balance load limitations.

Figures 18 and 19 present an isometric view of the PSP pressure distributions and a composite of PSP ratioed images. respectively. The primary differences relative to $M=0.50$ are the persistence of the wing vortex pressure signature at $x / c=$ 0.75 . and less evidence of vortex breakdown effects along the rear portion of the wing at $\alpha=20$ degrees. Increasing the Mach number from 0.50 to 0.70 weakens the leading-edge vortices and reduces the adverse longitudinal pressure gradient through which the vortices must traverse (ref. 19). Consequently, the vortex interaction will diminish, and the vortices may be able to persist in a stable form to higher angles of attack.

Comparison of the PSP pressure coefficients to the critical value of -0.779 indicates that there are large regions of locally supersonic flow on the wing surface. The development of locally supercritical flow on a highly-swept wing at a free-stream Mach number of 0.70 is consistent with the results presented in ref. 19.

\section{Baseline Fillet, $M=0.85$}

Figures 20(a) and 20(b) compare the distributions of the PSP and ESP upper surface static pressure coefficients at $M=0.85$ and $\alpha=16$ and 20 degrees. An isometric view of the PSP pressure 
distributions and a composite of the PSP ratioed images are presented in figs. 21 and 22 , respectively.

The in-situ calibrations of the PSP measurements yield very good agreement with the corresponding ESP data at both angles of attack in fig. 20 . In contrast to the results obtained at $M=0.50$ and 0.70 , the strake and wing vortices maintain distinct surface pressure footprints in figs. 20 and 21 up to, and including, $\alpha=20$ degrees. This trend indicates that increasing the Mach number decreases the direct interaction between the strake and wing vortices. The strake vortex pressure footprint is more peaked in fig. 20(a), fig. 20(b), and fig. 21, whereas the wing vortex pressure signature is typically broad with more subtle local maxima. Most of the experimental pressure coefficients exceed the critical value of -0.302 , which indicates that the upper surface flow is primarily supersonic at $M=0.85$.

The PSP ratioed images at $\alpha=10$ degrees in figure 22 suggest the presence of a normal shock wave just upstream of $x / c=$ 0.75 . The shock does not appear to be of sufficient strength, however, to affect the stability of the strake or wing vortices. For example, the PSP and ESP pressure distributions at $x / c=0.75$ and $x / c=0.90$ are representative of stable vortical flows. In addition, the corresponding LVS images reveal a stable, "donut-shaped" strake vortex. The wing vortex is not visible in the LVS flow visualization because of insufficient local condensation. The presence of this shock wave is not apparent at higher angles of attack, which may be the result of a three-dimensional relief effect (ref. 19) associated with the stronger strake and wing vortices. The pressure distributions, PSP images, and LVS flow visualization results suggest that the vortices are stable over the wing up to the highest angle of attack of 20 degrees. However, a review of the LVS videotape at $\alpha=20$ degrees with the light sheet located near the wing trailing edge revealed an expansion and unsteadiness of the vortical flows, which are indicative of vortex breakdown onset.

The PSP ratioed images typically reveal the highest suction pressure levels in a region beginning near the strake-wing junction and extending to approximately the $75 \%$ chord station. This region is denoted by colors ranging from blue to purple. The vortex that is shed from the wing leading edge is stronger than the strake vortex (ref. 20 ), and it induces significant suction pressures over a portion of the wing upper surface. The vortex feeding sheet does not remain attached to the leading edge because of the moderate wing sweep and the influence of the strake vortex. As a result, the wing vortex moves inboard and upward away from the surface, and its induced effect on the wing surface pressure field diminishes. The strake vortex is no longer fed by leading-edge vorticity downstream of the strake-wing junction, yet its surface pressure footprint is most intense in this region. This effect may be caused by its downward displacement toward the wing surface as a result of its interaction with the wing vortex.

\section{Baseline Fillet, $M=0.95$}

Figures 23(a) and 23(b) compare the distributions of the PSP and ESP upper surface static pressure coefficients at $M=0.95$ and $\alpha=16$ and 20 degrees. An isometric view of the PSP pressure distributions and a composite of the PSP ratioed images are presented in figs. 24 and 25, respectively. The PSP and ESP measurements exhibit good quantitative agreement, and they both capture the distinct strake and wing vortex footprints that persist up to $\alpha=20$ degrees. Direct interaction, or intertwining, of the strake and wing vortices does not occur at this Mach number, which was also inferred from the results at $M=0.85$. The available LVS images reveal both the strake and wing vortices. The 
strake vortex features more local condensate and is approximately circular in cross section, whereas the wing vortex appears as a flattened. elliptically-shaped region with low condensate level. Both vortices are in proximity to the wing upper surface. There is no indication of vortex instability in the pressure distributions. PSP images, or LVS flow visualization. For example. the pressure distributions in fig. 24 show that the suction pressure levels increase with increasing angle of attack up to the highest test angle of attack. An expansion and unsteadiness of the vortex flows were not apparent in the LVS flow visualization. Furthermore, the PSP images in figs. 23 and 25 clearly show the strake vortex surface pressure signatures persisting to the wing trailing edge. The wing vortex pressure signature is also more persistent at this Mach number, since its feeding sheet remains attached to the leading edge to a greater spanwise extent compared to lower Mach numbers. The attachment/detachment of the feeding sheet at the leading edge was observable in the LVS flow visualization by a band of condensate along the outer edge of the wing vortex.

A comparison of the experimental pressure coefficients to the critical value indicates that the flow is supercritical at all pressure measurement stations and angles of attack, except for a small region near the strake centerline at $x / c=0.25$ and angles of attack of 16 degrees or less.

\section{Baseline Fillet, $M=1.20$}

Figures 26(a) and 26(b) compare the distributions of the PSP and ESP upper surface static pressure coefficients at $M=$ 1.20 and $\alpha=16$ and 20 degrees. Figures 27 and 28 present an isometric view of the PSP pressure distributions and a composite of the PSP ratioed images, respectively.

Reasonable agreement is observed between the PSP and ESP pressure measurements, although there is more scatter between the two measurement techniques compared to the results obtained at lower Mach numbers. This trend is consistent with the higher mean relative error that was previously cited at $M=1.20$.

The rate of increase of the maximum vortex-induced suction pressure levels at this supersonic free-stream Mach number is modest compared to the results obtained at the subsonic Mach numbers. The PSP and ESP surface pressures at $x / c=0.75$ and $x / c=$ 0.90 may be approaching a limiting value. For example, the maximum suction pressure coefficients at these measurement stations are approximately -0.85 , which is about 86 percent of the vacuum pressure coefficient of -0.992 at this Mach number. Suction pressure levels approximately 90 percent of the vacuum limit were obtained in previous experiments of slender wings at supersonic speeds (refs. 21 and 22).

The results obtained at $M=1.20$ indicate that the strake and wing vortices are stable, in mutual proximity, but do not interwine at any location over the wing up to $\alpha=20$ degrees. In addition. the PSP and LVS images suggest that the wing vortex feeding sheet is attached to the leading edge to nearly the wing tip, which is consistent with the persistence of the wing vortex pressure signature over most of the wing upper surface at this Mach number.

\section{Summary of Mach Number Effect with Baseline Fillet}

The effect of Mach number on the PSP ratioed images at $\alpha=16$ and 20 degrees is presented in figures 29 and 30 , respectively. A common color coding was not used in the PSP images; the comparisons are solely intended to illustrate significant qualitative differences caused by Mach number changes at the selected angles of attack.

The PSP images in figs. 29 and 30 provide qualitative evidence of the reduced interaction of the strake and wing vortices and the ability of the vortices to more 
effectively traverse the wing pressure field at the transonic Mach numbers.

The results obtained on the baseline double delta wing model are consistent with experimental data reported in ref. 19 on a leading-edge extension (LEX) and 65degree cropped delta wing configuration. The analysis in ref. 19 indicated that increasing the Mach number decreased the vortex strengths, decreased the direct interaction of the strake and wing vortices, and delayed vortex breakdown to higher angles of attack.

\section{Parabolic Fillet, $M=0.50$}

Figure 31 compares the PSP and ESP pressure coefficients obtained with the parabolic fillet at $M=0.50$ and $\alpha=16$ and 20 degrees. Figures 32 and 33 present an isometric plot of the PSP pressure distributions and a composite of the PSP ratioed images, respectively, for a range of angle of attack from 10 to 20 degrees. The installation of a different fillet required the removal of the PSP and base coating tested with the baseline fillet and the application of a new coating on the entire upper surface of the strake and wing.

The parabolic fillet is designed to eliminate the leading-edge discontinuity at the strake-wing junction and to promote a single vortex system above the wing. The PSP and ESP pressure measurements capture the suction pressure signature of a dominant leading-edge vortex that is fed by vorticity shed from the strake and wing leading edges. The parabolic fillet is unable to maintain a single vortex, however, because of the significant change in the local sweep angle along the span of the wing. Consequently, the LVS images in fig. 31, the PSP pressure distributions in fig. 32 , and the PSP ratioed images in fig. 33 provide the clearest evidence that the primary vortical flow from the strake and wing "tears away" from the leading edge and a second, corotating vortex forms along the outer portion of the wing. The signature of this corotating vortex is not apparent in the pressure distributions and the PSP images at $\alpha=16$ and 20 degrees in figs. 31(a) and $31(\mathrm{~b})$, since the vortex moves inboard and upward from the wing surface as a result of a strong interaction with the primary leading-edge vortex. The available LVS flow visualization images at these angles of attack are the only source of data that confirm the continued presence of the smaller, weaker co-rotating vortex which "orbits" about the dominant leading-edge vortical flow. This effect is particularly evident at $x / c=0.90$, where the combined vortex system induces a single pronounced suction peak. Asymmetric vortex breakdown is apparent in the PSP and LVS images in fig. 31(b) and fig. 33 at $\alpha=20$ degrees. The wing with parabolic fillet generates a much stronger vortex than the baseline fillet. However, the higher-strength vortex system is more prone to vortex breakdown caused by an adverse longitudinal pressure gradient and to the presence of small asymmetries and discontinuities in the model geometry.

An indication of the strength of the leading-edge vortex with the parabolic fillet is provided by a comparison of the experimental pressure coefficients in figs. 31 and 32 to the critical pressure coefficient of -2.133 at $M_{\infty}=0.50$. A region of locally supercritical flow exists underneath the vortex system at $x / c=0.75$ and 0.90 beginning at an angle of attack of 14 degrees (fig. 32). This pocket of supersonic flow persists up to the highest test angle of attack of 20 degrees.

The dominance of the leading-edge vortex with the parabolic fillet is clearly illustrated in the isometric plot of the PSP pressure distributions for the range of angle of attack in fig. 32. The effect of vortex breakdown is not manifested in this plot, since breakdown first occurred on the nonpressure-instrumented right-hand side of the wing. The intense surface pressure response 
and asymmetric vortex breakdown are shown in the composite of PSP ratioed images in fig. 33 .

\section{Parabolic Fillet, $M=0.70$}

The PSP and ESP pressure distributions at $M=0.70$ and $\alpha=16$ and 20 degrees are compared in figure 34 . LVS images were not available for these angles of attack at $M=0.70$. Figures 35 and 36 present, respectively, an isometric plot of the PSP pressure distributions and a composite of PSP ratioed images for this Mach number.

The global calibrations of the PSP yielded very good agreement with the ESP measurements at both angles of attack in fig. 34. The pressure distributions at $\alpha=10$ and 12 degrees in figs. 35 and the PSP ratioed images in fig. 36 indicate that the parabolic fillet results in a vortex flow field that is very different from the design goal. Specifically, the PSP pressure distributions at $x / c=0.75$ reveal multiple suction pressure peaks that are induced by three co-rotating vortices. This multiple-vortex system is also apparent in the PSP ratioed images. A strong mutual interaction occurs between the vortices, which coil around each other to such an extent that they induce a single. pronounced suction pressure peak at $x / c=$ 0.90 in fig. 35. Comparison of the experimental pressure coefficients to the critical value of -0.779 at $M=0.70$ indicates that locally supercritical flow exists underneath the vortices.

The three-vortex system persists at $\alpha=$ 14 degrees (fig. 35), and the region of supersonic flow underneath the vortices broadens at this higher angle of attack. A notable change in the global PSP surface pressure response in fig. 36 is the appearance of vortex breakdown on the right-hand side of the wing at this angle of attack. Previous flow visualization that was performed at this Mach number in the NASA LaRC 7- by 10-Foot High Speed Tunnel did reveal the violent onset of asymmetric vortex breakdown at an angle of attack of approximately 14 degrees.

Symmetry of the vortex breakdown pattern is restored in the PSP images at $\alpha=$ 16 degrees in fig. 34(a) and fig. 36. LVS flow visualization was not performed at angles of attack of 16 degrees or higher because of balance instrumentation load limits in the atmospheric 7 - by 10 -foot facility. This was not an issue in the 8-Foot TPT testing. However, LVS flow visualization was also precluded in the 8foot IPI for another reason. namely, prohibitively large amounts of water injection to achieve local condensation. The triple-vortex suction peak is absent at $\alpha=16$ degrees and $x / c=0.75$ as a result of the upstream advance of vortex breakdown toward this measurement station. Instead. a single vortex pressure signature occurs with locally supercritical flow. Fully-established vortex breakdown at $x / c=0.90$ causes a significant reduction in the suction pressure peak, a broadening of the spanwise pressure distribution, and subcritical flow across the entire local semispan.

Interestingly, vortex breakdown does not appear to advance significantly further upstream as the angle of attack increases to 20 degrees (fig. 34(b)). A similar inference is made based on the PSP ratioed images in fig. 36. A distinct suction pressure peak is maintained at $x / c=0.75$, and a suction peak with locally supercritical flow reappears at $x / c=0.90$. It is speculated that the rate of advance of vortex breakdown over the wing was slowed by the establishment of flow field symmetry beginning at approximately $\alpha=16$ degrees.

\section{Parabolic Fillet, $M=0.85$}

The PSP and ESP pressure distributions at $M=0.85$ and $\alpha=16$ and 20 degrees are compared in figure 37 . LVS flow visualization was not performed with this fillet at $M=0.85$. Figures 38 and 39 present, respectively, an isometric plot of the PSP 
pressure distributions and a composite of PSP ratioed images for this Mach number.

Good agreement is apparent between the calibrated PSP measurements and the discrete ESP tap data. Most of the flow on the wing upper surface is supersonic, since the experimental pressure coefficients typically exceed the critical value of -0.302 at $M=0.85$. The PSP pressure distributions and PSP ratioed images in figs. 38 and 39 reveal multiple-vortex development at $\alpha=$ 10 and 12 degrees. Evidence of at least two co-rotating vortices is apparent in the PSP pressure distributions. The corresponding PSP ratioed images suggest the presence of three vortices, which is similar to the result obtained at $M=0.70$. Unlike the lower Mach number, asymmetric vortex breakdown does not occur at $\alpha=14$ degrees and $M=0.85$. A significant change does occur in the surface pressure response at $\alpha=14$ degrees (figs. 38 and 39), but in a symmetric fashion. The region of high suction pressures and the signature of a leading-edge vortex along the midsection of the wing are no longer evident in the PSP pressure distributions and the PSP ratioed image at $\alpha=14$ degrees. Beginning at $\alpha=$ 14 degrees, the results in figs. 37-39 suggest the vortex system that is shed from the strake and a portion of the parabolic fillet tears away from the leading edge and follows a nearly streamwise path over the wing. The pressure footprint of this vortical flow is apparent in the distributions at $x / c=0.75$ and $x / c=0.90$. The pressure distributions along the outer region of the wing are broad and flat, which may be associated with separated flow at the wing leading edge without reattachment. It is speculated that fully-established vortex breakdown occurs over the rear portion of the wing, and the resultant expanded, rotating flow induces the flatter pressure distribution at $\mathrm{x} / \mathrm{c}=0.90$ in fig. 37(b). The effects of vortex breakdown on the double delta wing appear to be more subtle at $M=0.85$ compared to $M=0.50$ and 0.70 and are more difficult to infer from the pressure distributions, particularly without corroborative evidence from the LVS flow visualization.

\section{Parabolic Fillet, $M=0.95$}

Good agreement is obtained between the PSP and ESP pressure measurements at $M=$ 0.95 and $\alpha=16$ and 20 degrees as shown in figure 40. The pressure distributions and PSP ratioed images in figs. 41 and 42 indicate that multiple vortex shedding is a dominant flow-field feature that persists through most of the range of angle of attack. A photographic account of multiple vortex shedding from highly-swept wings at transonic speeds is provided in ref. 23. In contrast to the results obtained at $M=0.85$, the vortex that is shed from the main wing remains attached to the wing leading edge up to at least $\alpha=18$ degrees. As a result, the character of the pressure distributions is the same for all angles of attack within this range. This trend is depicted in the isometric plot in fig. 41. It is speculated that vortex sheet tearing occurs at $\alpha=20$ degrees (fig. 40(b)) with a subsequent reduction in the suction pressure levels along the outer portion of the wing. Direct evidence of vortex breakdown is not apparent at this Mach number. In fact, the surface pressure response in the PSP ratioed images at $\alpha=20$ degrees in figs. 40 (b) and 42 suggest that the strake vortex persists in a stable form to the wing trailing edge. Corroborative LVS flow visualization was not performed with this fillet at $M=0.95$. Comparison of the PSP and ESP pressure coefficients to the critical value of -0.088 indicates that the flow along the wing upper surface is supersonic, except for a small region near the centerline of the strake at the lower angles of attack.

\section{Parabolic Fillet, $M=1.20$}

The PSP and ESP pressure measurements at $M=1.20$ and $\alpha=16$ and 20 degrees are shown in figure 43. An isometric plot of the pressure distributions and a composite of the PSP ratioed images 
at all angles of attack are presented in figs. 44 and 45. respectively. The PSP and ESP measurements exhibit good quantitative agreement in fig. 43. The pressure distributions and PSP ratioed images in figs. 43-45 reveal multiple vortex development at each angle of attack. The character of the pressure distributions and the corresponding color-coded PSP surface pressure response maps in figs. 43-45 are similar at all angles of attack, which is indicative of a stable, multiple vortex system. The peak suction pressure coefficient at $x / c=0.90$ and $\alpha=20$ degrees in fig. 43(b) and fig. 44 is approximately 86 percent of the vacuum limit of -0.992 at $M=1.20$, which is similar to the result obtained with the baseline fillet.

\section{Summary of Mach Number Effect with Parabolic Fillet}

The pressure distributions indicate that the highly-peaked pressure distributions that are characteristic of the subsonic Mach number conditions change to less-peaked and broader distributions at the transonic Mach numbers. This trend is consistent with a weaker but wider vortex system that may influence more of the wing upper surface at the higher Mach numbers. In addition, the direct interaction and coiling of the multiple vortices that are shed from the wing leading edge is diminished or eliminated at the higher Mach numbers. As a result, the vortices maintain distinct signatures in the surface pressure distributions. This trend is revealed in the PSP pressure field response in figures 46 and 47, which show the effect of the Mach number on the PSP ratioed images at $\alpha=16$ and 20 degrees. These images also show that the flow-field asymmetries or vortex breakdown that occur at $M=0.50,0.70$, and 0.85 are not apparent at $M=0.95$ and 1.20 .

\section{Diamond Fillet, $M=0.50$}

A third application of PSP was required for testing the diamond fillet, and the resultant PSP and ESP measurements obtained at $M=0.50$ and $\alpha=16$ and 20 degrees are shown in figures $48(a)$ and 48(b), respectively. An isometric plot of the calibrated PSP pressure distributions is presented in figure 49 , and the PSP ratioed images at all angles of attack are shown in the figure 50 .

The diamond fillet is designed to promote multiple vortices near the strakewing intersection. The pressure distributions, PSP images, and LVS flow visualization results in figs. 48 to 50 confirm the establishment of multiple vortices and associated surface pressure signatures. Satisfactory calibrations of the PSP were obtained using the discrete ESP pressure tap data. and the two measurement techniques exhibit very good agreement in fig. 48. As an example of the complex flow field developed by the diamond fillet, the PSP ratioed images at the lower angles of attack in fig. 50 reveal the signatures of five corotating vortices, including one from the strake, two from the diamond fillet, and two along the wing. The available LVS images in fig. 48 also reveal a flow field characterized by multiple vortices. The strake vortex is the dominant feature of the flow field, and the interaction and coiling of the vortices typically yields dual- or singlepeak pressure distributions at the higher angles of attack, depending on how the vortices orbit about each other. Onset of vortex breakdown at $\alpha=20$ degrees is indicated by the diffusion of the condensate pattern in the LVS image at $x / c=0.90$ in fig. 48(b) and a corresponding significant decrease in the maximum suction pressure level at this station.

A comparison of the PSP and ESP pressure coefficients to the critical value of -2.133 at $M=0.50$ indicates that the flow is subsonic except possibly at $\alpha=18$ degrees and $x / c=0.75$ in fig. 49 , where a small pocket of supercritical flow occurs underneath the interacting vortex flows. 
Diamond Fillet, $M=0.70$

The PSP and ESP measurements continue to exhibit good agreement at $M=$ 0.70 and $\alpha=16$ and 20 degrees, as shown in figs. 51(a) and 51(b), respectively. The calibrated PSP pressure distributions and the PSP ratioed images in figs. 51-53 are qualitatively similar to the results obtained at $M=0.50$ up to $\alpha=16$ degrees. However, asymmetric vortex breakdown is inferred from the PSP ratioed images at the higher angles of attack in figs. 51(b) and 53. LVS flow visualization was not conducted on the diamond fillet at this Mach number. Vortex breakdown occurs over the non-pressureinstrumented right-hand side of the wing. Note that it would not be possible to infer the presence of vortex breakdown on the basis of the pressure distributions on the left-hand side. Large regions of locally supercritical flow exist underneath the vortices based on a comparison of the experimental pressure coefficients to the critical value of -0.779 at $M=0.70$. The development of pockets of supersonic flow may contribute to the onset of flow asymmetries. In contrast, the flow was observed to be symmetric at the same angles of attack at $M=0.50$ where the pressure coefficients corresponded primarily to subcritical conditions.

\section{Diamond Fillet, $M=0.85$}

Figure 54 compares the PSP and ESP pressure measurements at $M=0.85$ and $\alpha=16$ and 20 degrees. An isometric plot of the PSP pressure distributions and a composite plot of the PSP ratioed images are shown in figs. 55 and 56, respectively. Good quantitative agreement is obtained between the two pressure measurement techniques in fig. 54 . The majority of pressure coefficient values exceed the critical value of -0.302 at $M=0.85$, which indicates that large regions of locally supersonic flow exist near the wing surface.

The PSP ratioed images in figs. 54 and 56 suggest the presence of a normal shock centered about the wing root chord at an axial location immediately downstream of the fillet. The PSP color-coded surface pressure maps at $\alpha=10,12$, and 14 degrees in fig. 56 indicate that, if a shock exists over the wing surface, it is not of sufficient strength to cause vortex breakdown. For example, the strake vortex surface pressure signature persists to the wing trailing edge at these angles of attack.

A marked change in the surface pressure response occurs in a symmetric fashion at $\alpha=16$ degrees (fig. 54(b) and fig. 56). The color-coded images indicate that the strake vortex no longer persists to the wing trailing edge. In addition, the more intense blue and purple colors induced by the vortical flows along the main wing at lower angles of attack are absent at angles of attack greater than or equal to 16 degrees. This effect may be caused, in part, by a tearing of the vortex sheet from the wing leading edge. The decrease in the maximum vortexinduced suction pressures and the flattening of the pressure distribution at $x / c=0.90$ and $\alpha=20$ degrees in fig. 54(b) and fig. 55 are consistent with an expanded rotating flow corresponding to a burst vortex system.

\section{Diamond Fillet, $M=0.95$}

Figure 57 shows good agreement between the PSP and ESP pressure distributions at $M=0.95$ and $\alpha=16$ and 20 degrees. The isometric plot of the calibrated PSP pressure distributions and the ratioed PSP images at angles of attack from 10 to 20 degrees are presented in figs. 58 and 59 , respectively. The pressure coefficients generally exceed the critical value of -0.088 at $M=0.95$, and only a small pocket of subcritical flow is apparent near the strake centerline at the lower angles of attack. The pressure distributions and PSP ratioed images in figs. 57-59 indicate that multiple vortices are the dominant feature of the flow at all angles of attack. The spanwise pressure distributions frequently exhibit an irregular character that reflects the numerous 
vortices shed from the strake. fillet. and wing leading edges. The PSP images in figs. 57 and 59 show that the strake vortex pressure footprint persists to the wing trailing edge up to the highest test angle of attack of 20 degrees. In addition. the wing vortex flow remains attached to the leading edge to a higher angle of attack compared to lower Mach numbers. Consequently, its direct interaction with the strake vortex is diminished. A partial detachment of the wing vortex feeding sheet from the leading edge may occur at $\alpha=20$ degrees, which is inferred from the pressure distributions in fig. 57(b) and from the color code changes along the outer wing in the PSP images in fig. 57(b) and fig. 59. There is no evidence of vortex breakdown onset over the wing up to and including $\alpha=20$ degrees.

\section{Diamond Fillet, $M=1.20$}

The complex nature of the vortex flow field with the diamond fillet that was observed at the subsonic free-stream conditions is also apparent at $M=1.20$ in figs. 60,61 , and 62 . Although numerous vortices are shed along the strake, fillet, and wing leading edges, the overall surface pressure response is dominated by large regions of vorticity from the strake and wing. These regions remain largely distinct and persist to the wing trailing edge up to and including an angle of attack of 20 degrees. The PSP pressure mappings in figs. 60 and 62 suggest that the vortex system shed from the fillet merges with the strake vortex. The character of the PSP pressure distribution at a given measurement station in fig. 61 is not very sensitive to changes in the angle of attack, and the overall suction pressure level increases with the angle of attack. These trends are indicative of a stable flow field above the wing, despite the complexity of the multiple vortex system with the diamond fillet. The highest experimental pressure coefficient obtained at $\alpha=20$ degrees is approximately 85 percent of the vacuum limit, which is similar to the results obtained with the baseline and diamond fillets.

\section{Summary of Mach Number Effect with Diamond Fillet}

The Mach number effect on the upper surface static pressure distributions is complicated at $x / c=0.75$ and 0.90 . because of the interactions of multiple vortices and the occurrence of symmetric and asymmetric vortex breakdown. In general, the maximum suction pressure levels are lower at the higher Mach numbers, but the vortex-induced pressure distributions are broader and, therefore, influence a larger portion of the wing. At the higher Mach numbers. direct interaction of the vortical flows is reduced or eliminated. and the strake and wing vortex pressure footprints are more distinguishable with increased lateral spacing. Inconsistent results are obtained at $\alpha=20$ degrees because of the effects of symmetric vortex breakdown at $M=0.50$ and asymmetric breakdown at $M=0.70$. Interestingly, the onset of asymmetric vortex breakdown on the righthand side of the wing at the latter Mach number appears to serve as a relieving effect on the left-hand side such that a high suction pressure peak is obtained.

The qualitative effect of the Mach number on the PSP ratioed images at $\alpha=16$ and 20 degrees is illustrated in figs. 63 and 64 , respectively. The PSP images indicate that the symmetric or asymmetric vortex breakdown at $M=0.50$ to $M=0.85$ is not apparent in the surface pressure mappings at $M=0.95$ and $M=1.20$. The regions of blue and purple colors that signify high vortexinduced suction pressures are more distinct. streamwise, and persistent at the higher Mach numbers. This trend is consistent with diminished direct interaction of the vortical flows and with a wing vortex sheet that is less prone to detachment from the leading edge. 


\section{Effect of Wing Fillet Shape on Surface Static Pressure Response}

The calibrated PSP pressure distributions and the PSP ratioed images are presented in this section to illustrate the effect of the wing fillet shapes on the surface static pressure response. Representative results obtained at each Mach number are presented in figures 65 through 89 , which include the PSP pressure distributions (and estimated error bars) corresponding to the three fillet configurations and composite figures of the PSP ratioed images at selected angles of attack.

Separate data files were created that contained the values of the measured ESP pressure coefficients and the corresponding PSP image intensity ratios that were obtained using the PSP image processing application in ref. 13. These files were subsequently used in simple linear regression analyses using the application in ref. 18 to estimate the global mean PSP pressure coefficient response at each combination of Mach number, angle of attack, and fillet geometry. Ninety-five percent confidence intervals for the mean response at selected pixel locations in the PSP images were constructed using the following equation (ref. 24):

$$
\widehat{C}_{p . P S P} \pm t_{1-\alpha_{s} / 2, N-2} s\left(\widehat{C}_{p . P S P}\right)
$$

where $\widehat{C}_{p, P S P}$ is the point estimate of the mean response at the desired PSP pixel location. The corresponding estimated standard deviation of the mean response is

$$
\begin{aligned}
& s\left(\widehat{C}_{p, P S P}\right)= \\
& \left.\operatorname{MSE}\left[\frac{1}{N}+\frac{\left(\left(I / I_{o}\right)-\overline{I / I_{o}}\right)^{2}}{\sum_{i=1}^{N}\left(\left(I / I_{o}\right)-\bar{I} / I_{o}\right)^{2}}\right]\right)^{1 / 2}
\end{aligned}
$$

The critical value from the $\mathrm{t}$-distribution corresponding to a 5 percent level of significance, $\alpha_{\mathrm{s}}$, and 45 degrees of freedom is

$$
t_{1-\alpha_{s} / 2, N-2}=t_{0.975,45}=2.014
$$

The mean square error, MSE, is an unbiased estimator of the population variance. A point estimate of MSE was determined from each regression analysis and was based on 45 degrees of freedom. The intensity ratios at (1) the desired pixel location, (2) the pixel location corresponding to the $i^{\text {th }}$ ESP tap, and (3) averaged over all $N$ ESP pressure tap locations are expressed, respectively, as

$$
\left(I / I_{o}\right),\left(I / I_{o}\right)_{i}, \overline{I / I_{o}}
$$

The $95 \%$ confidence intervals are depicted in the following figures as error bars centered about the estimated mean PSP pressure coefficient.

$M=0.50$

Figure 65 shows the effect of the wing fillet shape on the spanwise distributions of the PSP pressure coefficient at $\alpha=20$ degrees. An isometric plot of the fillet effect on the PSP pressure distributions at $\alpha=20$ degrees is presented in fig. 66. The fillet effect on the PSP ratioed images at $\alpha=16,18$, and 20 degrees is illustrated in figs. 67-69.

The upstream influence of the fillet geometry is small at $x / c=0.25$ (fig. 65(a) and fig. 66). The results obtained at $x / c=$ 0.75 and $x / c=0.90$ in figs. $65(\mathrm{~b}), 65(\mathrm{c})$, and 66 indicate that the fillet shape has a statistically and practically significant effect on the PSP pressure distributions. The geometry change at the strake-wing junction promotes a redistribution of the vortexinduced suction pressures across the local semispan. The PSP ratioed images in figs. 67-69 reveal a global effect of the fillet geometry on the surface pressure response on the main wing. The most significant effect is associated with the parabolic fillet, which promotes much higher vortex-induced suction peaks at $x / c=0.75$ and $x / c=0.90$ and an overall increase in the vortex suction 
pressure levels across the local semispan compared to the baseline and diamond fillets. The parabolic fillet encourages the development of a single dominant vortex, although other smaller, weaker vortices are shed from the outer portion of the wing leading edge. Note. however, that the PSP pressure distributions do not reflect the asymmetric vortex breakdown with the parabolic fillet at $\alpha=20$ degrees that is apparent in the PSP ratioed images in fig. 69. The diamond fillet also promotes an overall increase in the vortex-induced suction pressure levels at $x / c=0.75$ and $x / c=0.90$, although this effect is less pronounced in comparison to the parabolic fillet. Onset of symmetric vortex breakdown at an angle of attack of approximately 20 degrees occurs with the baseline and diamond fillets. This effect is suggested in the PSP images in fig. 69. Only the parabolic fillet results in PSP pressure coefficients that exceed the critical value of -2.133 at this Mach number, The region of locally supercritical flow is limited to a small pocket on the main wing underneath the leading-edge vortex at the higher angles of attack.

\section{$M=0.70$}

The effect of the wing fillet shape on the spanwise distributions of the PSP pressure coefficient at $\alpha=20$ degrees is shown in fig. 70. An isometric plot of the fillet effect on the PSP pressure distributions at $\alpha=20$ degrees is presented in fig. 71 . The fillet effect on the PSP ratioed images at $\alpha=16$, 18 , and 20 degrees is illustrated in figs. $72-$ 74.

The global pressure response on the wing upper surface continues to exhibit sensitivity to the fillet shape at $M=0.70$. However, the magnitude of the fillet effect is less pronounced at this higher Mach number. Furthermore, the flow field is prone to early onset and asymmetric vortex breakdown with the parabolic and diamond fillets. All three fillet configurations are characterized by multiple leading-edge vortex development and the development of regions of locally supersonic flow induced by the vortical flows. The regions of supercritical flow are identified on the basis of PSP pressure coefficient values that exceed the critical value of -0.779 at this Mach number. The diamond fillet appears to promote an overall increase in the wing upper surface suction pressure level. However, the potential benefit of the diamond fillet that might be inferred from the pressure distributions at this Mach number is tempered by the observed vortex instabilities and asymmetries in the PSP ratioed images in figs. 73 and 74 .

$M=\mathbf{0 . 8 5}$

The effect of the wing fillet shape on the PSP pressure distributions at $\alpha=20$ degrees is shown in fig. 75. An isometric plot of the fillet effect on the PSP pressure distributions at $\alpha=20$ degrees is presented in fig. 76 . The fillet effect on the PSP ratioed images at $\alpha=16.18$. and 20 degrees is illustrated in figs. 77-79.

The pressure distributions in figs. 75 and 76 indicate that the ability of the fillet geometry to effect large-scale changes to the vortex-dominated pressure distributions about the double-delta wing diminishes at this higher Mach number. Examination of the PSP ratioed images in figs. 77-79 do reveal significant changes in the global surface pressure field response caused by the fillet shape. The altered vortex patterns implicit in the PSP images promote a redistribution of the surface static pressures but, generally, do not result in an overall increase in the suction pressure levels on the wing. The fillet effectiveness is also affected by the occurrence of symmetric vortex breakdown, which is common to the baseline, parabolic, and diamond fillets at the higher angles of attack. Comparison of the PSP pressure coefficients to the critical value of -0.302 at this Mach number suggests large regions of supercritical flow on the wing upper surface with all three fillet shapes. 
$M=0.95$

The effect of the wing fillet shape on the PSP pressure distributions at $\alpha=20$ degrees is shown in fig. 80. The isometric plot of the PSP pressure distributions at this angle of attack is presented in fig. 81. The composite PSP ratioed images at $\alpha=16,18$, and 20 degrees are shown in figs. 82-84.

A consistent overall increase in the suction pressure levels on the main wing was observed at angles of attack less than 20 degrees as a result of adding either the parabolic or diamond fillets at $M=0.95$ (data not shown in this paper). Neither the parabolic or diamond fillet was distinctly superior to the other in terms of the magnitude of the suction pressure level increase. A departure from this trend occurs at $\alpha=20$ degrees (fig. 80), where the parabolic fillet decreases the overall suction pressure levels compared to the baseline fillet. This may be caused by an apparent vortex-sheet tearing phenomenon that is inferred from the PSP ratioed images at $\alpha=18$ and 20 degrees in figs. 83 and 84 , respectively. The detachment of the leading-edge feeding sheet would be expected to reduce the favorable vortexinduced effects on the outer wing flow. The PSP images show common features in the wing surface pressure pressure field response such as a well-defined strake vortex footprint that persists to the trailing edge. Discernible differences are evident in the surface pressure response in the region of the outer wing where the parabolic and diamond fillets appear more effective in maintaining an organized (vortex) flow structure, except as noted above at $\alpha=20$ degrees.

\section{$M=1.20$}

The effect of the wing fillet shape on the PSP pressure distributions at $\alpha=20$ degrees is shown in fig. 85. The isometric plot of the PSP pressure distributions at this angle of attack is presented in fig. 86. The composite PSP ratioed images at $\alpha=16,18$, and 20 degrees are shown in figs. 87-89.
The fillet effects on the PSP pressure distributions are manifested primarily as a redistribution of the vortex-induced suction pressures compared to the baseline configuration (figs. 85 and 86). Vortex breakdown does not occur at any angle of attack up to 20 degrees at $M=1.20$. The fillets cause visible changes in the leadingedge vortex pressure response in the PSP images in figs. 87-89. However, the overall pressure response maps exhibit common features for all three fillets, which include stable vortical flows from the strake and wing and evidence of an organized flow structure along the outer wing up to $\alpha=20$ degrees.

\section{Effect of Wing Fillet Shape on Lift, Drag, and Pitching Moment Coefficients}

Figures 90-94 show the effect of the fillet shape on the lift, drag, and pitching moment coefficients at $M=0.50,0.70,0.85,0.90$ and 1.20. The parabolic fillet promotes a large increase in the lift coefficient, a decrease in the drag coefficient at a given lift coefficient, and nose-down pitching increments at $M=0.50$ (fig. 90) compared to the baseline configuration. These trends are attributed to the development of a single, dominant leading-edge vortex over the wing. The abrupt lift decrease, drag increase, and unstable break in the pitching moment curve above $\alpha=18$ degrees with the parabolic fillet are associated with the onset of asymmetric vortex breakdown over the wing. The diamond fillet yields more modest effects on the lift, drag, and pitching moment. The onset of symmetric vortex breakdown occurs at lower angles of attack for the diamond and baseline fillet configurations, and the nonlinear trends are less severe compared to the parabolic fillet.

The asymmetric vortex breakdown that was observed with the parabolic and diamond fillets at $M=0.70$ causes 
significant nonlinearities in the lift. drag. and pitching moment curves in fig. 91 . These configurations are clearly less desirable when compared to the more predictable aerodynamic coefficient trends exhibited by the baseline configuration. It is noted that the aerodynamic asymmetries may be caused by small asymmetries in the model geometry, particularly in the regions where the sharp leading edges of the main wing and the fillets abut each other. Symmetric detachment of the vortex feeding sheet from the leading edge of the outer wing. which was observed in the LVS flow visualization and inferred from the PSP images, promotes aerodynamic discontinuities of lesser magnitude at $M=0.85$ in fig. 92 .

Aerodynamic nonlinearities are generally absent at $M=0.95$ (fig. 93). since vortex breakdown. symmetric or asymmetric, does not occur within the test range of angle of attack. The parabolic and diamond fillets promote a consistent increase in lift and a decrease in drag at a given lift compared to the baseline fillet. The lone discontinuity in the lift. drag, and pitching moment with the parabolic fillet at the highest angle of attack is attributed to a vortex sheet tearing phenomenon which was discussed in the previous section.

The character of the lift. drag, and pitching moment coefficient curves are similar for all three fillet configurations at $M=1.20$ (fig. 94). The absence of discontinuities in the aerodynamic characteristics is consistent with the observed stable vortical flows and attached leading-edge feeding sheet along the outer wing that were inferred from the PSP pressure distributions and PSP ratioed images. Small lift increments, drag-due-tolift reductions, and nose-down pitching moment increments are observed with the parabolic and diamond fillets.

\section{Concluding Remarks}

A pressure-sensitive paint (PSP) technique was applied in a wind tunnel experiment in the NASA Langley Research Center 8-Foot Transonic Pressure Tunnel to quantify the effect of wing fillets on the global vortex-induced surface static pressure field about a sharp leading-edge $76^{\circ} / 40^{\circ}$ double delta wing. or strake-wing. model at subsonic and transonic speeds. Global calibrations of the PSP were obtained at subsonic and transonic Miach numbers using an in-situ method featuring the simultaneous acquisition of electronically-scanned pressures (ESP) at 47 discrete locations on the model. The mean error in the PSP measurements relative to the ESP data was dependent on the Mach number and typically increased to several percent at the transonic conditions. The PSP pressure distributions and false-colored surface pressure maps revealed the vortex-induced pressure signatures at all Mach numbers and angles of attack. Small fillets having a parabolic or diamond planform situated at the strake-wing intersection were designed to manipulate the flow-field interaction over the main wing. The fillets caused global changes in the vortex-dominated surface pressure field that were effectively captured in the PSP measurements. The vortex surface pressure signatures were compared to available off-surface vortex cross-flow structures obtained using a laser vapor screen (LVS) flow visualization technique. The fillets exhibited a potential to increase the overall suction pressures on the main wing and to sustain an organized flow structure along the outer wing region. However, the ability of the fillets to effect favorable changes in the vortex flow interactions was limited by a sensitivity to asymmetric vortex breakdown and detachment of the leading-edge vortex sheet along the outer wing panel at the subsonic and low transonic Mach numbers. The fillet effects on the PSP pressure distributions, PSP surface pressure maps, and the 
observed leading-edge vortex flow characteristics were consistent with the trends that were apparent in the measured lift, drag, and pitching moment coefficients, including aerodynamic discontinuities or nonlinearities.

\section{References}

1. McLachlan, B. G.; Bell, J. H.; Kennelly, R. A.; Schreiner, J. A.; Smith, S. C.; Strong, J. M.; Gallery, J.; and Gouterman, M.: Pressure Sensitive Paint Use in the Supersonic High-Sweep Oblique Wing (SHOW) Test. AIAA92-2686, June 1992.

2. McLachlan, B. G.; and Bell, J. H.: Pressure-Sensitive Paint in Aerodynamic Testing. Experimental Thermal and Fluid Science, Vol. 10, 1995, pp. 470-485.

3. Erickson, G. E.: Wind Tunnel Application of a Pressure-Sensitive Paint Technique to a Faceted Missile Model at Subsonic and Transonic Speeds. NASA-TM-2004-212991, February 2004.

4. Gonzalez, H. A.; Erickson, G. E.; McLachlan, B. G.; and Bell, J. H.: Effects of Various Fillet Shapes on a 76/40 Double Delta Wing from Mach 0.18 to 0.70 . Paper No. 48-1, presented at the RTO AVT Symposium on "Advanced Flow Management: Part A Vortex Flows and High Angle of Attack for Military Vehicles," Loen, Norway, 7-11 May 2001, published in RTO-MP069(I).

5. Erickson, G. E.: Overview of Selected Measurement Techniques for Aerodynamics Testing in the NASA Langley Unitary Plan Wind Tunnel. AIAA-2000-2396, June 2000.
6. Cunningham, A. M., Jr.; and den Boer, R. G.: Unsteady Low-Speed Wind Tunnel Test of a Straked Delta Wing, Oscillating in Pitch. AFWALTR873098, Pts. I-IV, 1987.

7. Kern, S. B.: Numerical Investigation of Vortex Flow Control Through Small Geometry Modifications at the Strake/Wing Junction of a Cropped Double Delta Wing. AIAA-92-0411, January 1992.

8. Braslow, A. L.; Hicks, R. M.; and Harris, R. V., Jr.: Use of Grit-Type Boundary-Layer Transition Strips on Wind-Tunnel Models. NASA TN D3579, 1966.

9. Hall, R. M.; Erickson, G. E.; and Fox, C. H., Jr.: Evaluation of Gritting Strategies for High Angle of Attack Using Wind Tunnel and Flight Test Data for the F/A-18. NASA TP-1998207670, May 1998.

10. Rhew, R. D.: NASA LaRC Strain Gage Balance Design Concepts. Presented at the First International Symposium on Strain Gauge Balances, NASA CP1999-2091/PT2, March 1999, pp. 525541. NASA TP-1998-207670, May 1998.

11. Brooks, C. W., Jr.; Harris, C. D.; and Reagon, P. G.: The NASA Langley 8Foot Transonic Tunnel Calibration. NASA TP 3437, 1994.

12. Fox, C. H., Jr.; and Huffman, J. K.: Calibration and Test Capabilities of the Langley 7- by 10-Foot High Speed Tunnel. NASA TM X-74027, May 1977.

13. Trosin, J.; and Hermstad, D.: PAINTCP V2.3 User's Guide. TN-94-8006-000048, Technical Note No. 48, Revision 1, NASA Ames Research Center, May 1995.

American Institute of Aeronautics and Astronautics 
14. Jagharghi, A. J.: User's Guide for Pressure Sensitive Paint and Processing Software (PSPAPS V3.1). ViGYAN, Inc. Internal Report, June 1995.

15. Erickson, G. E.; and Inenaga, A. S.: Fiber-Optic-Based Laser Vapor Screen Flow Visualization for Aerodynamic Research in Larger Scale Subsonic and Transonic Wind Tunnels. NASA TM 4514, 1994.

16. Jagharghi, A. J.; Cler, D. L.; Erickson, G. E.; Mitchell, M.; Lamb, M.; Gibson, L.S.; Farokhi, S.; Taghavi, R. R.; and Hazlewood, R.: Application of Pressure Sensitive Paint to Measurement of Global Surface Pressure for a Convergent-Divergent Nozzle and an Isolated Double Delta Wing at Transonic Speeds. AIAA-95-0639, January 1995.

17. Oglesby, D. M.; Puram, C. K.; and Upchurch, B. T.: Optimization of Measurements with Pressure Sensitive Paints. NASA TM 4695, 1995.

18. Many authors: JMP Version 5, User's Guide. SAS Institute Inc., ISBN 159047-070-2, 2002.
19. Erickson, G. E.: Wind Tunnel Investigation of the Interaction and Breakdown Characteristics of SlenderWing Vortices at Subsonic, Transonic, and Supersonic Speeds. NASA TP 3114, 1991.

20. Hemsch, M. J.; and Luckring, J. M.: Connection Between Leading-Edge Vortex Lift and Vortex Strength for Delta Wings. J. Aircr., vol. 27, no. 5, May 1990, pp. 473-475.

21. Wood, R. MA: Supersonic Aerodynamics of Delta Wings. NASA TP 2771, 1988.

22. Wood, R. L.; Wilcox, F. J., Jr.; Bauer, S.X.S.; and Allen, J. M.: Vortex Flows at Supersonic Speeds. NASA TP-2003$211950,2003$.

23. Campbell, J. F.; and Chambers, J. R.: Patterns in the Sky - Natural Visualization of Aircraft Flow Fields. NASA SP-514, 1994.

24. Neter, J.; Kutner, M. H.; Nachtstein, C. $\mathrm{J}$. ; and Wasserman, W.: Applied Linear Statistical Models. Fourth Edition, ISBN 0-256-11736-5, SCB McGrawHill, 1996. 


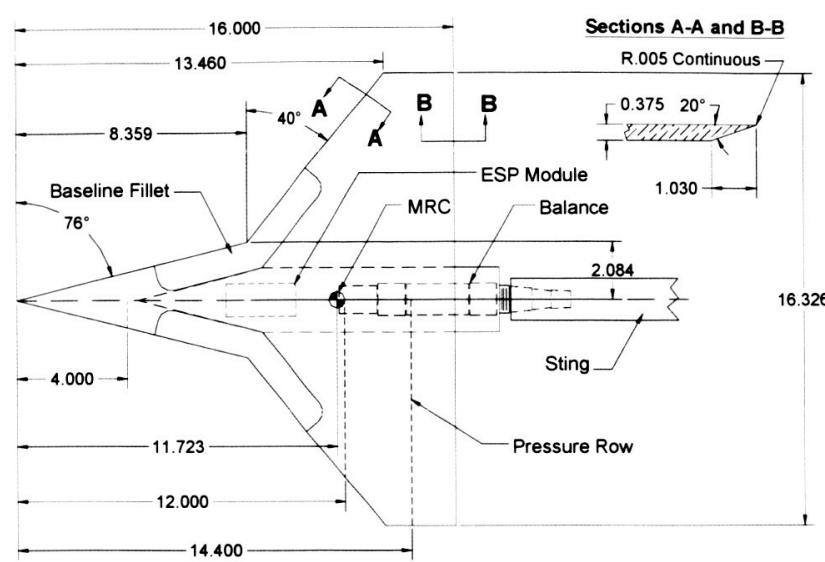

Figure 1. Planview of the double delta wing model with baseline fillet. (All dimensions are inches).

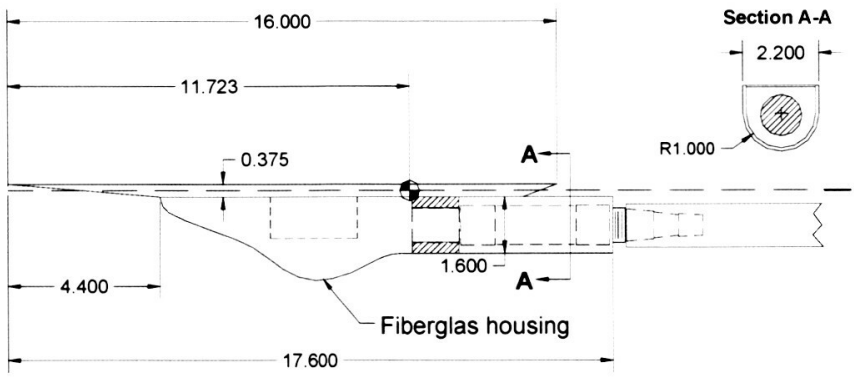

Figure 2. Sideview of the double delta wing model. (All dimensions are in inches).

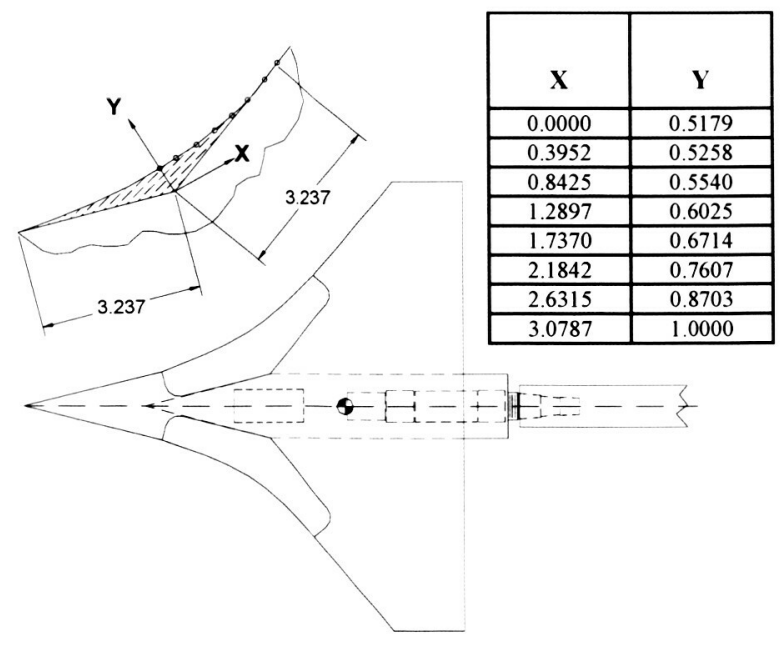

Figure 3. Planview of the double delta wing model with parabolic fillet. (All dimensions are in inches.)

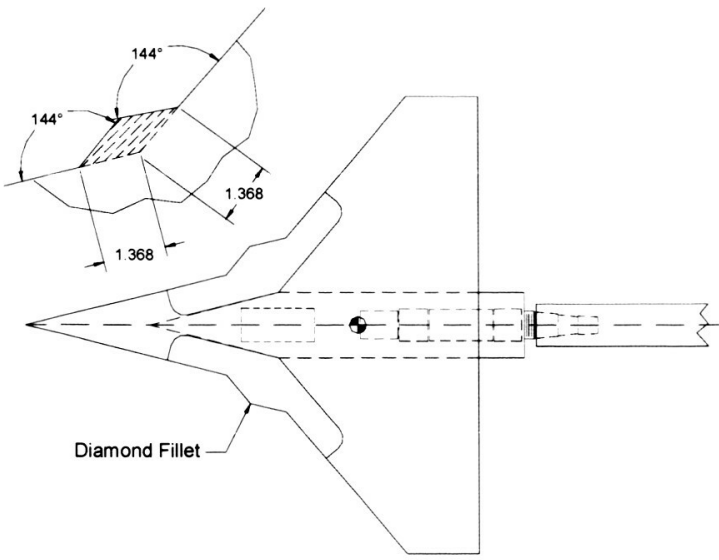

Figure 4. Planview of the double delta wing model with diamond fillet. (All dimensions are in inches.)

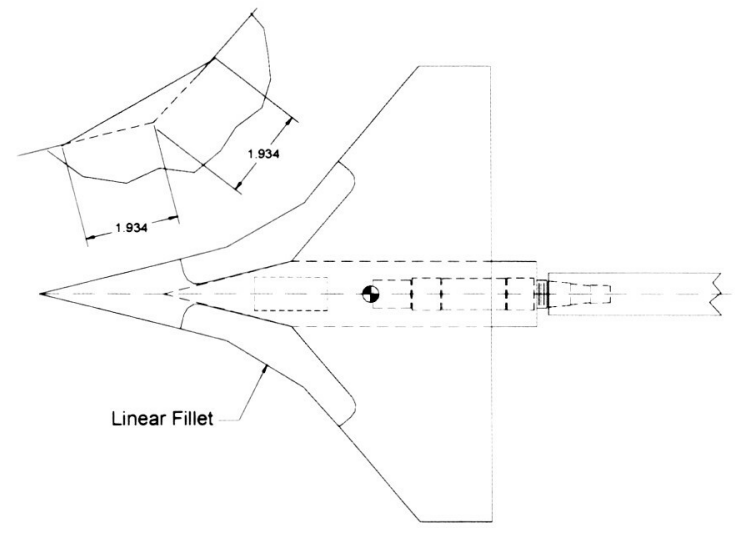

Figure 5. Planview of the double delta wing model with linear fillet (not used in PSP testing). (All dimensions are in inches.)

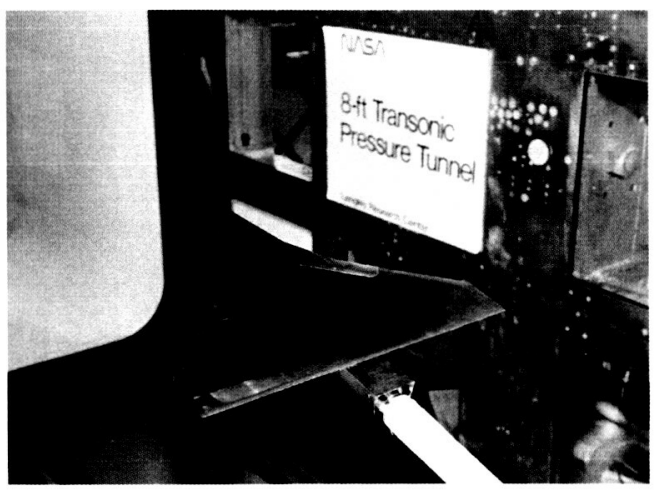

(a) Model installed in the test section of the NASA Langley Research Center (LaRC) 8-Foot Transonic Pressure Tunnel (8-Foot TPT).

Figure 6. Installation photographs of the double delta wing. (Note: PSP testing was not performed on the linear fillet shown in the photograph.). 


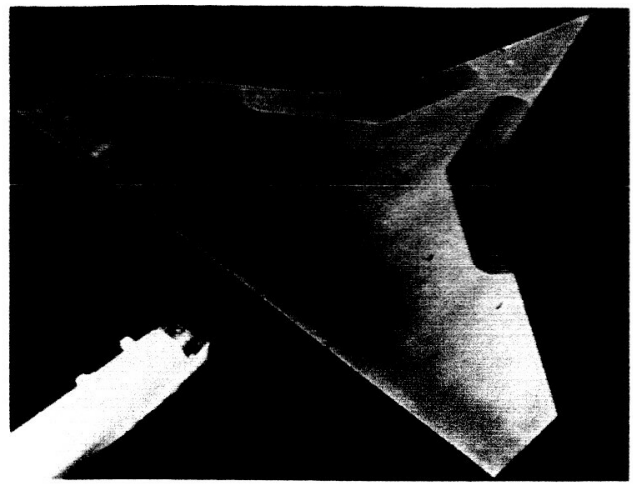

(b) Close-up photograph

Figure 6. Concluded.

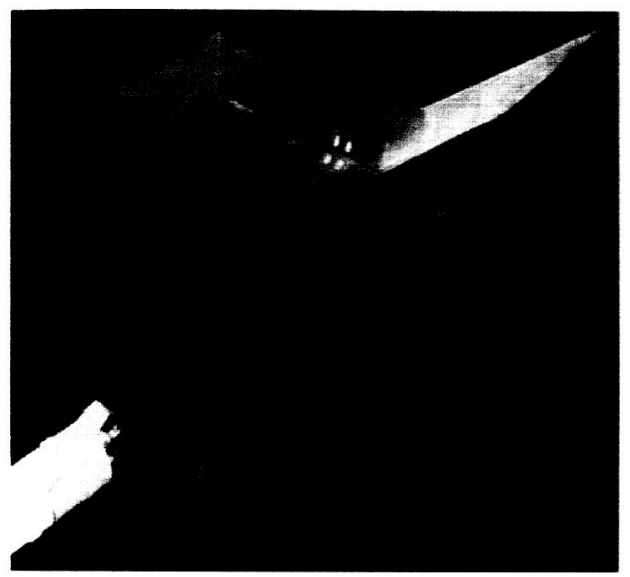

Figure 7. Close-up photograph of the double delta wing mode lower surface with balance and ESP instrumentation housing.

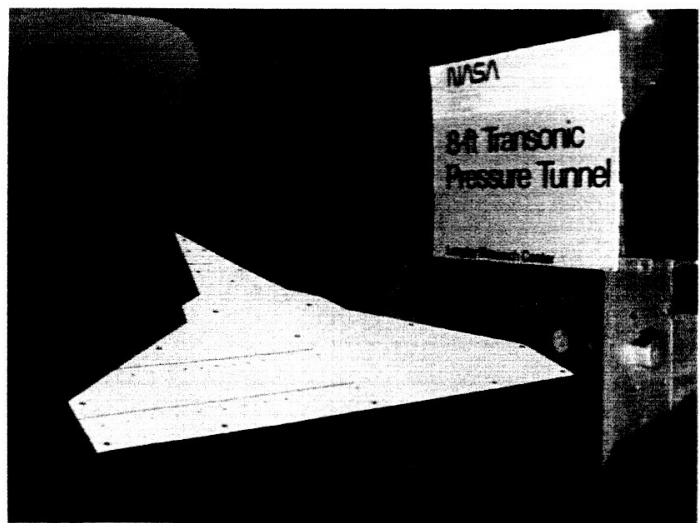

Figure 8. PSP coating applied to the double delta wing model with diamond fillet. (Note: Photograph was taken with a blue filter.)

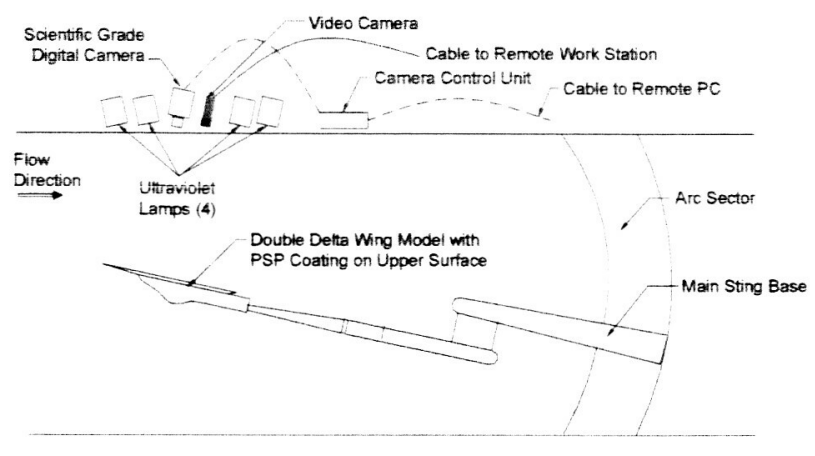

Figure 9. Sketch of main imaging system components in the NASA LaRC 8-Foot TPT pressure sensitive paint system.

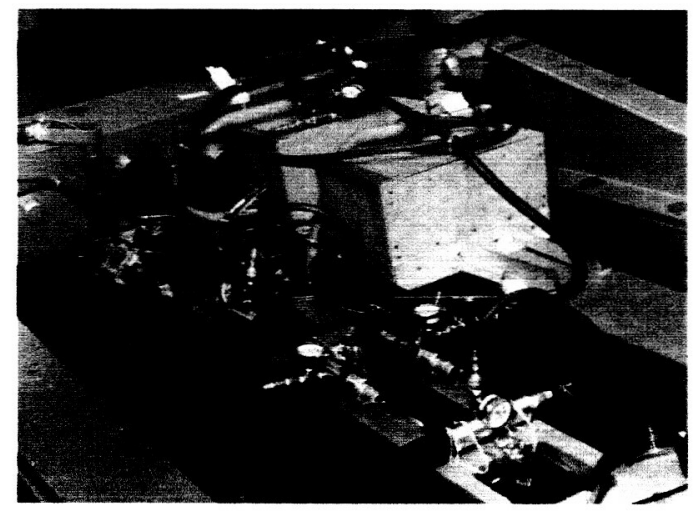

Figure 10. Photograph of PSP imaging components installed above the test section of the NASA LaRC 8-Foot TPT. (Note: PSP cameras are installed in a structural box beam and are not visible in the photograph).

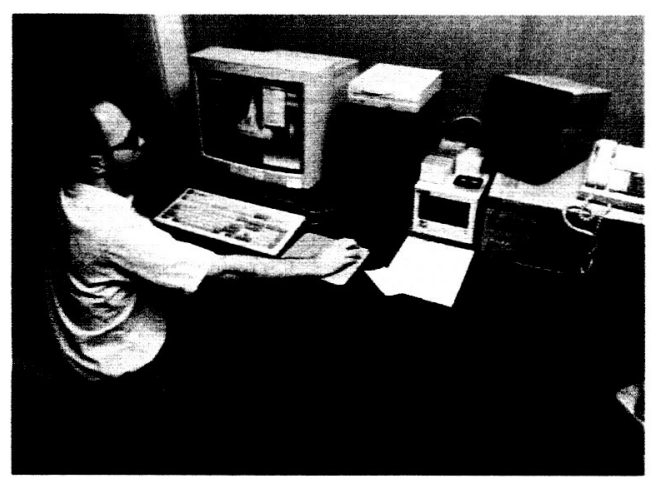

Figure 11. Photograph of PSP conventional video image acquisition and processing system in the control room of the NASA LaRC 8-Foot TPT

American Institute of Aeronautics and Astronautics 


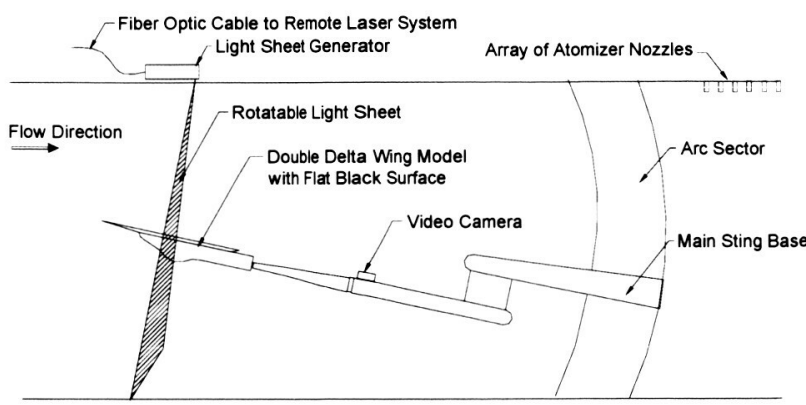

Figure 12. Sketch of the NASA LaRC 8-Foot TPT laser vapor screen flow visualization system.

\begin{tabular}{|cccccc|}
\hline & Wing Fillet & Method & Paint & $M_{\infty}$ & $\alpha$, deg \\
$\bigcirc$ & Baeline & ESP & Off & 0.50 & 20.01 \\
$\square$ & Baeline & ESP & On & 0.50 & 20.01 \\
\hline
\end{tabular}

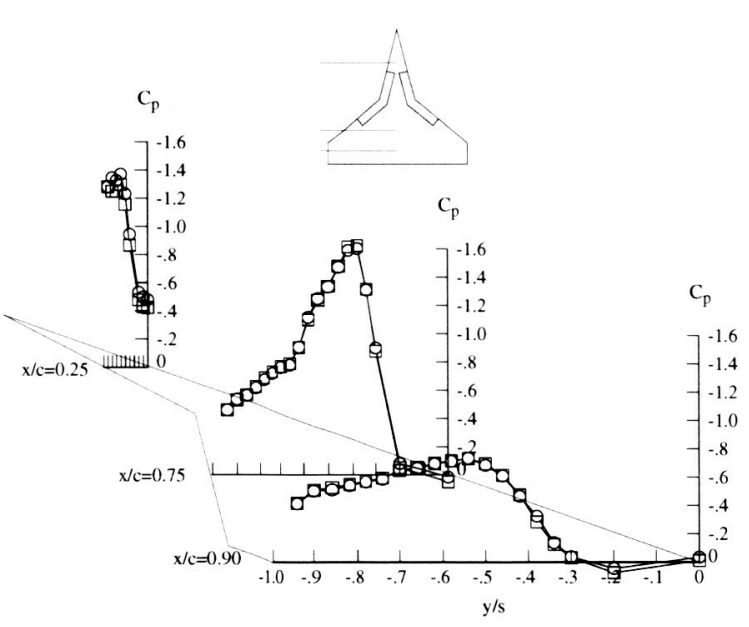

(a) $M=0.50$.

Figure 13. Comparison of unpainted and painted wing ESP pressure measurements with baseline fillet at $\alpha=20^{\circ}$.

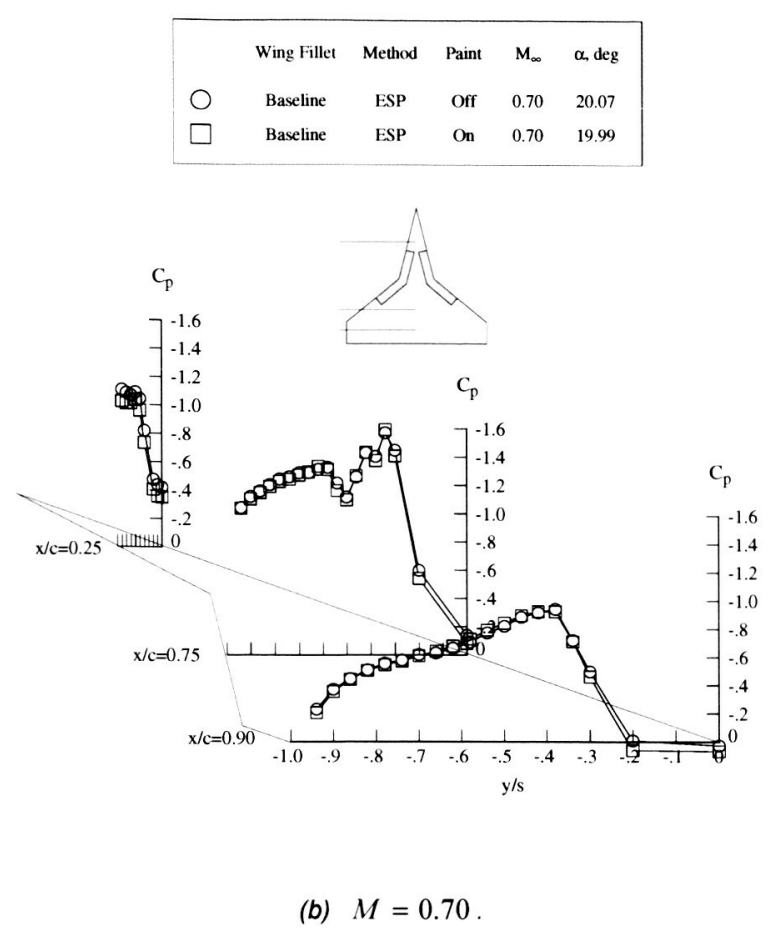

Figure 13. Continued
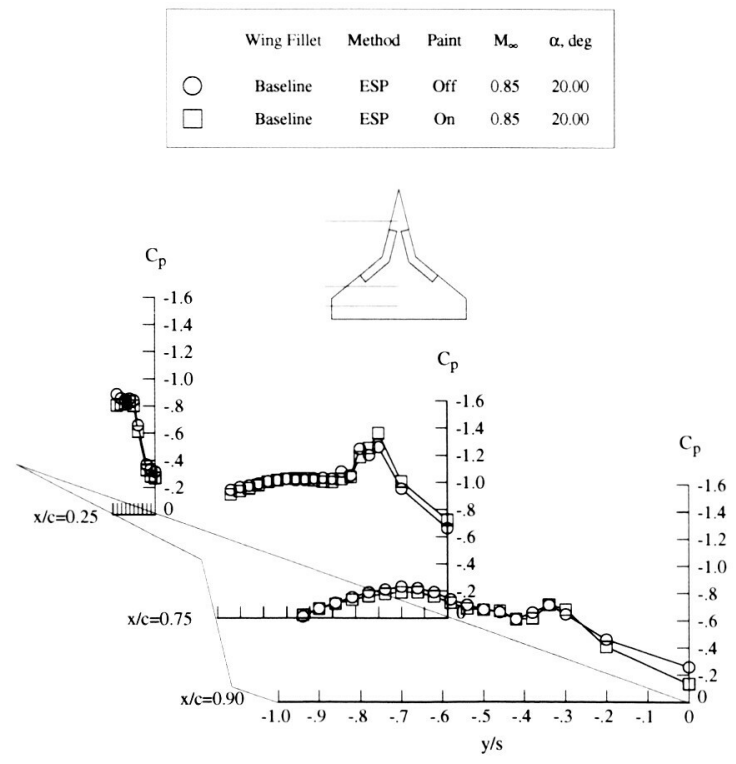

(c) $M=0.85$.

Figure 13. Continued. 


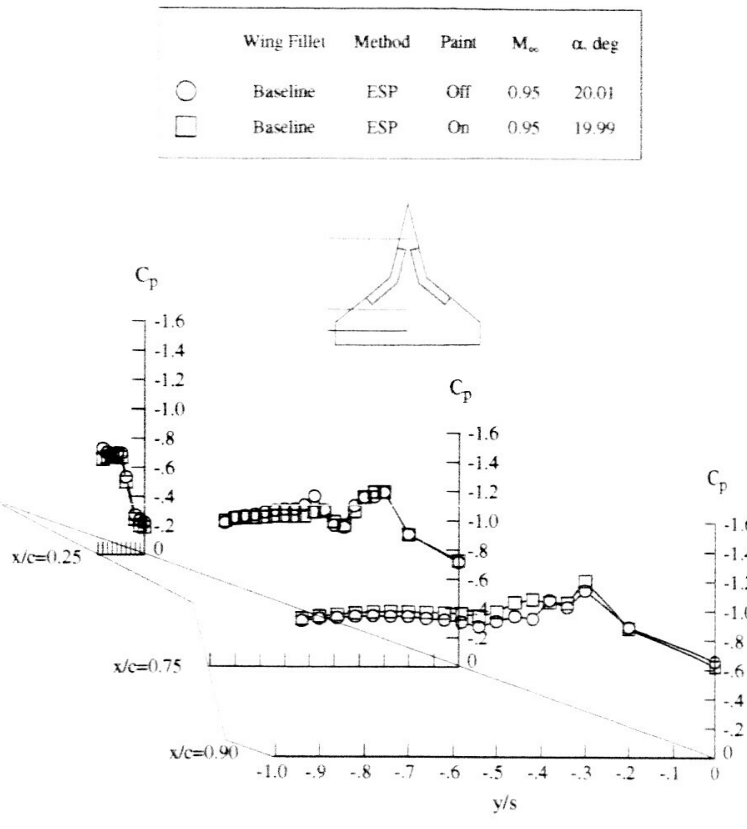

(d) $M=0.95$.

Figure 13. Continued

\begin{tabular}{llllll}
\hline & Wing Fillet & Method & Paint & $M_{\infty}$ & $\alpha$, deg \\
$\square$ & Baseline & ESP & Off & 1.22 & 19.99 \\
$\square$ & Baseline & ESP & On & 1.20 & 20.01 \\
\hline
\end{tabular}

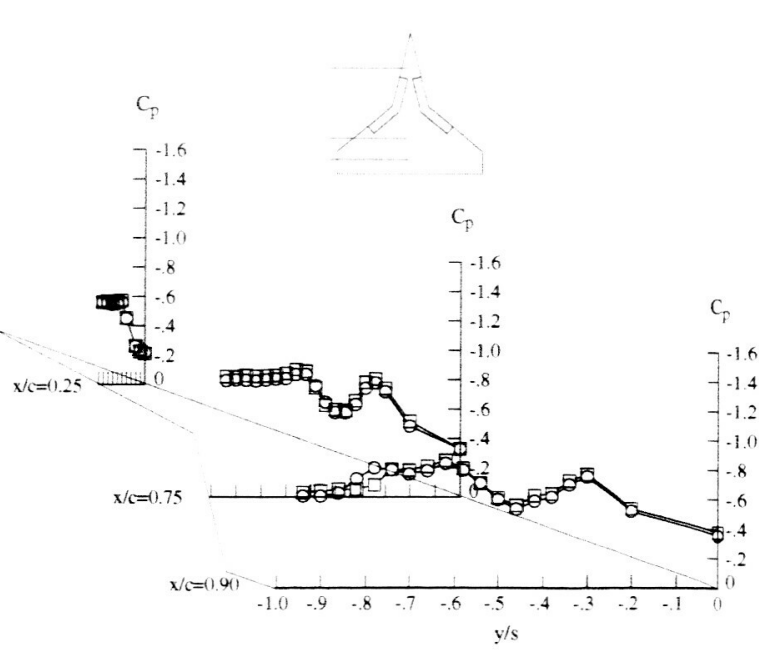

(e) $M=1.20$.

Figure 13. Concluded
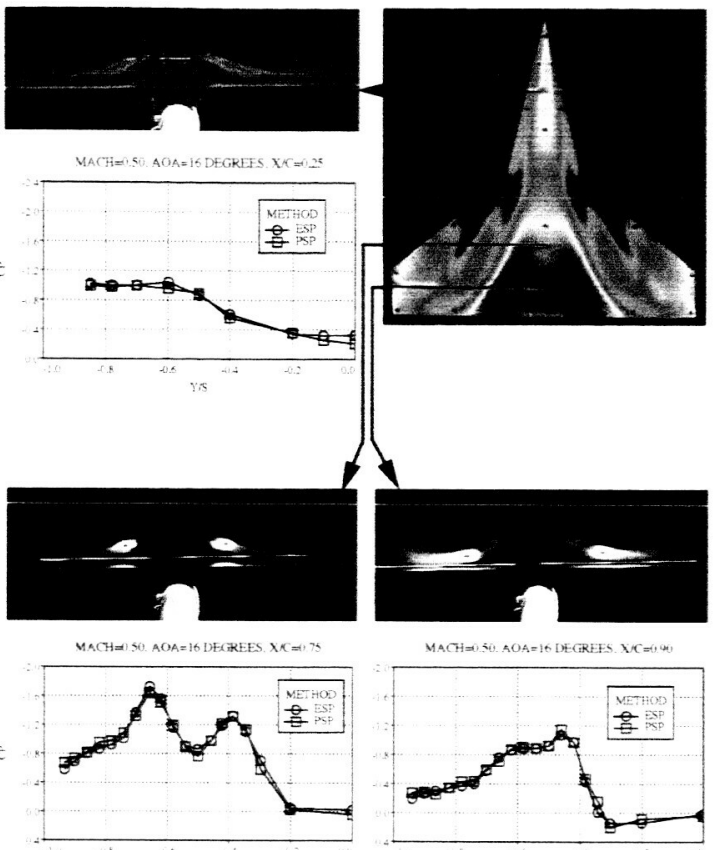

(a) $\alpha=16^{\circ}$

Figure 14. Composite plots of PSP and ESP pressure measurements and LVS flow visualization images with baseline fillet at $M=0.50$.

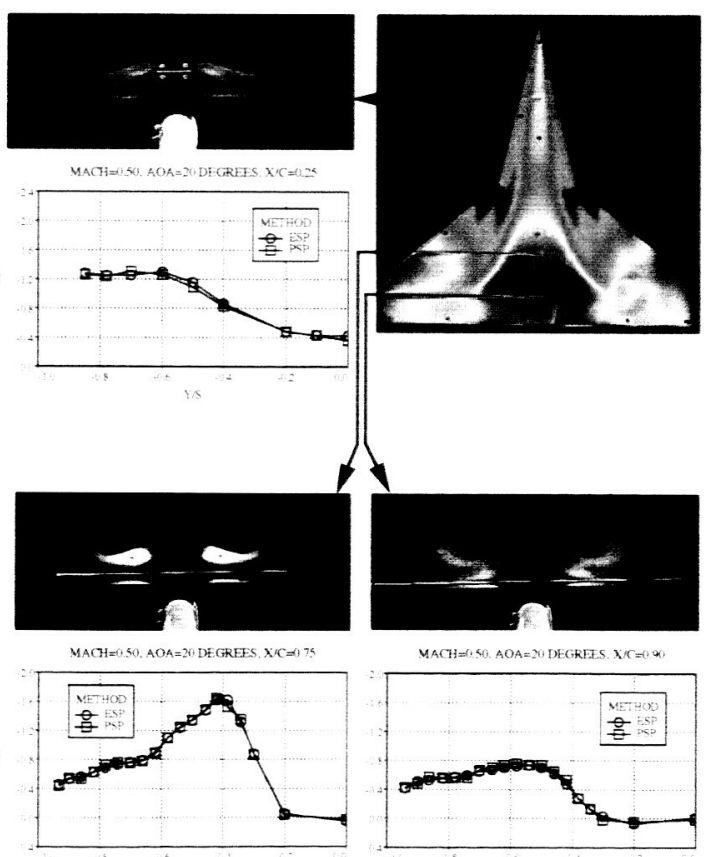

(b) $\alpha=20$

Figure 14. Concluded. 


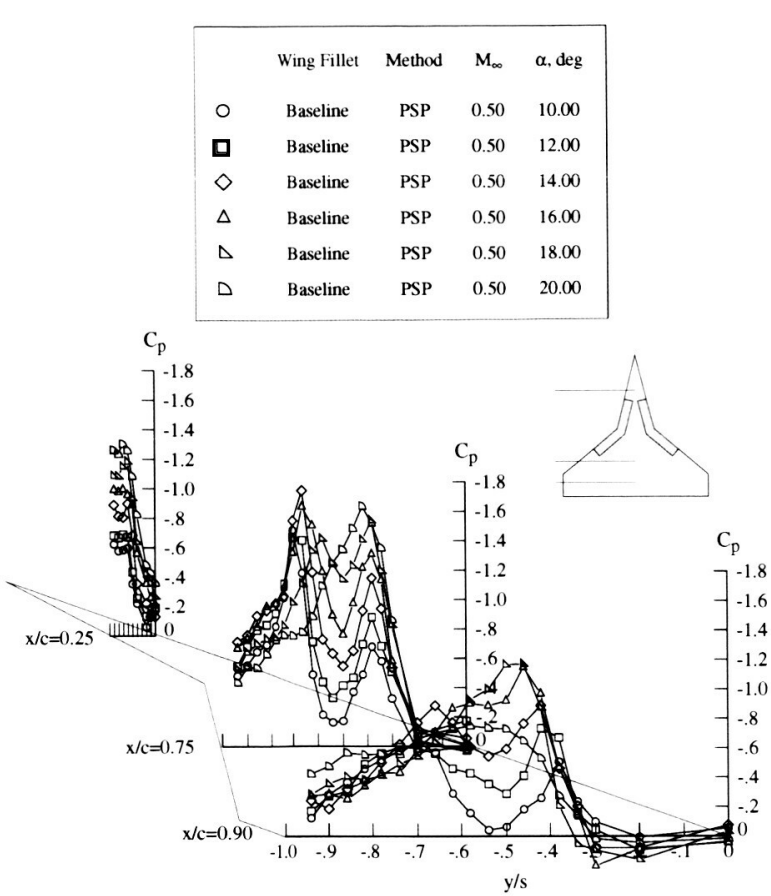

Figure 15. Effect of angle of attack on the PSP pressure distributions with baseline fillet at $M=0.50$.
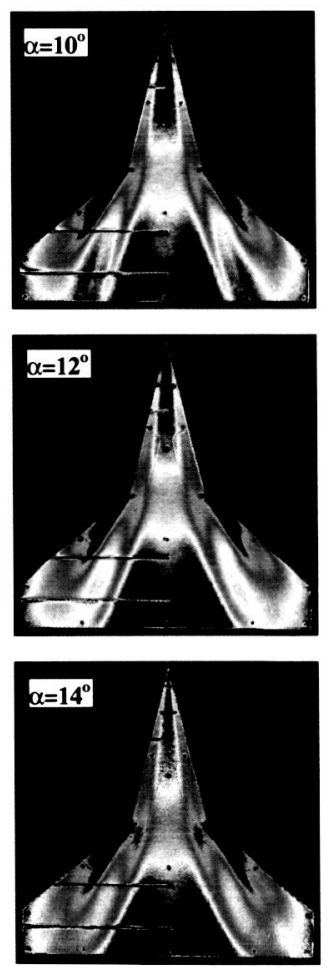

Figure 16. Effect of angle of attack on the PSP ratioed images with baseline fillet at $M=0.50$.
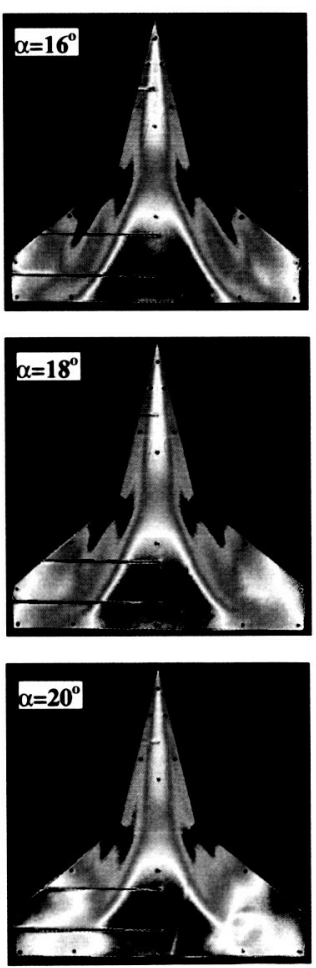

American Institute of Aeronautics and Astronautics
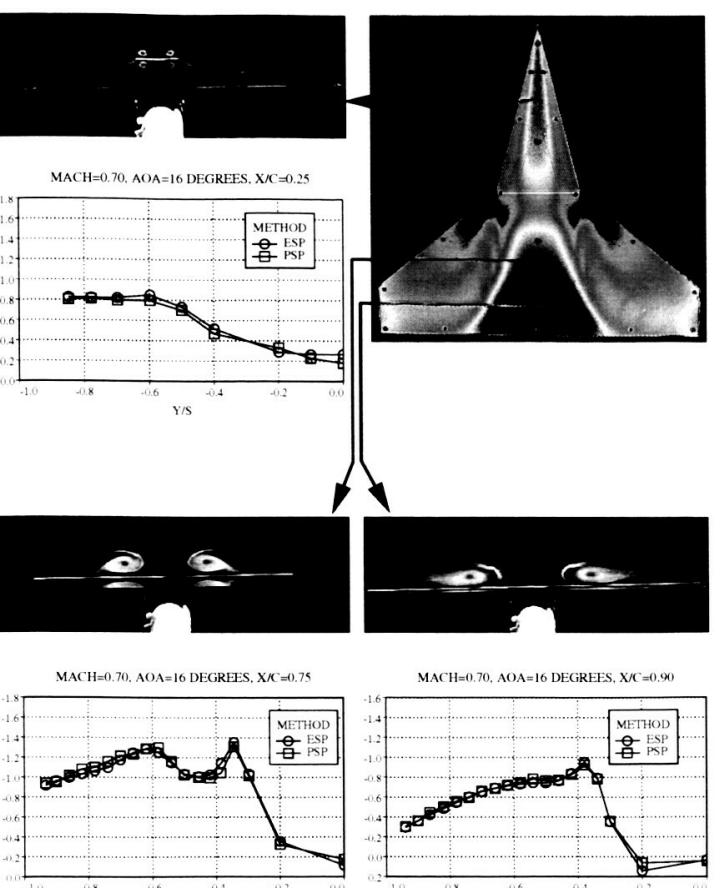

(a) $\alpha=16^{\circ}$.

Figure 17. Composite plots of PSP and ESP pressure measurements and LVS flow visualization images with baseline fillet at $M=0.70$
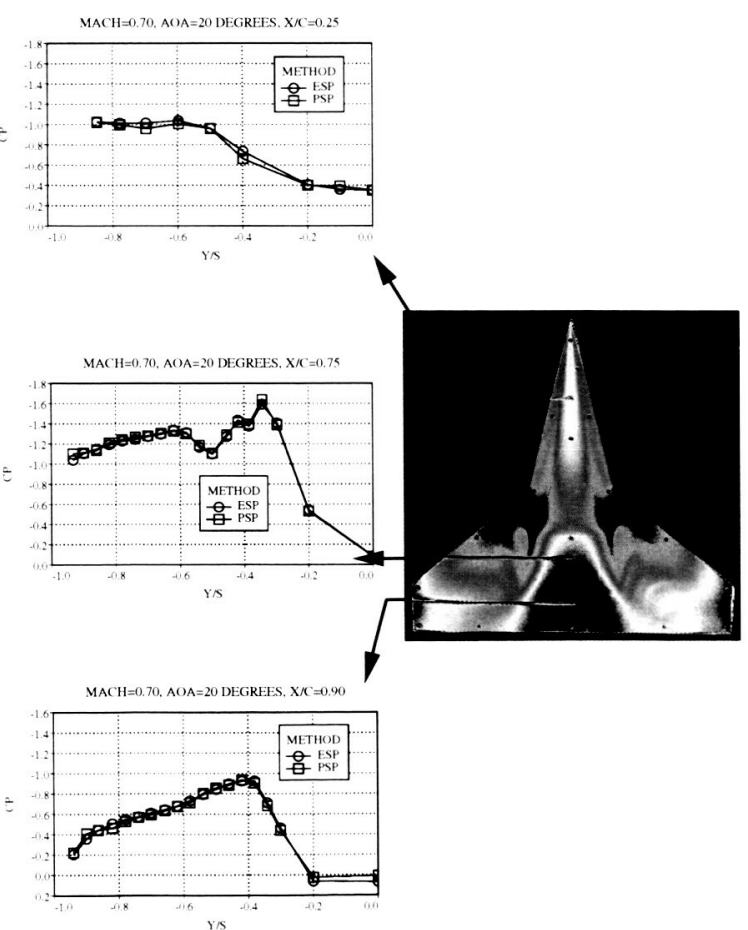

(b) $\alpha=20^{\circ}$.

Figure 17. Concluded. 